\title{
BREVE PRESENTACIÓN DE LOS SEMICONDUCTORES
}

\section{BRIEF PRESENTATION OF THE SEMICONDUCTORS}

Arturo Pérez París: Universidad de Alcalá de Henares. Madrid (España). arturo.perez@mixmail.com

\section{CURRÍCULUM VITAE}

Escuela Politécnica de la Universidad de Alcalá de Henares. Ingeniero electrónico y literato. Destacan sus estudios sobre aplicaciones eléctricas y motricidad sobre los que ha publicado varios artículos científicos.

\section{RESUMEN}

Hace un tiempo se pensaba que la tecnología basada en semiconductores era de procedencia extraterrestre y que empezó a desarrollarse a partir de los sucesos de Roswell. A lo largo de este artículo se pretende explicar la procedencia, principios y procesos de fabricación de los transistores, base de los circuitos integrados o chips. Sus características han permitido que se desarrollen con gran rapidez los componentes en estado sólido, o semiconductores, frente a las válvulas de vacío que les precedieron.

\section{PALABRAS CLAVE}

Semiconductores - Transistores - Circuitos integrados 


\begin{abstract}
Some time ago it was thought that semiconductor-based technology was extraterrestrial origin and that began to develop from the events of Roswell. Throughout this article is to explain the origin, principles and processes for manufacturing transistors based integrated circuits, or chips. Its characteristics have allowed to develop rapidly in the solid state components, or semiconductors, compared to vacuum tubes that preceded them.
\end{abstract}

\title{
KEY WORDS
}

Semiconductors - Transistors - ICs

\section{ÍNDICE}

1. Introducción

2. El Material Semiconductor

3. Clasificación de los semiconductores

4. El diodo

5. El transistor

6. Fabricación de componentes de estado sólido 


\section{TEXTO:}

\section{Introducción}

En números anteriores se presentó la implementación semiprofesional de placas de circuito impreso. En esta ocasión, hemos creído pertinente dar a conocer el proceso de fabricación de algunos dispositivos utilizados en los circuitos electrónicos así como sus propiedades. El trabajo, dada su extensión, lo hemos dividido en varias partes, como viene siendo habitual. En la anterior entrega tratamos de la fabricación de resistencias, condensadores, bobinas y núcleos comúnmente utilizados, transformadores y relés, los llamados componentes electrónicos pasivos. En el presente artículo haremos una breve y somera presentación de los semiconductores y sus más frecuentes aplicaciones.

Hace un tiempo, en un programa de televisión, escuché algo que me llamó la atención. Creo que fue el director de la revista Año Cero, quien comentaba que la tecnología basada en semiconductores era de procedencia extraterrestre y que empezó a desarrollarse a partir de los sucesos de Roswell. Yo, francamente, me sorprendí. ¿Cómo era posible tan poca memoria científico - histórica? Lo peor no es que este señor se creyera esto (o no, quien sabe), sino que al decirlo por la "sacrosanta" televisión provocó que mucha gente le tomara en serio, y lo que es peor, aceptaran semejante "barbaridad". No entraré en el debate de la existencia de extraterrestres. Dudo que seamos el único planeta con vida "inteligente" en todo el cosmos. Creo también que debido a lo enorme del universo, los contactos entre civilizaciones, de producirse, serán poco frecuentes. Mas cuando se produjeran, ¿no serían algo tan insólito y de tal envergadura que todos nos enteraríamos sin lugar a dudas? Veamos, si nos enteramos de las idas y venidas del "famosete" de turno ¿cómo podría ocultarse la toma de contacto de dos civilizaciones a escala planetaria con la intrincada red periodística que existe hoy por hoy? 
Francamente, esto me recuerda aquella ocasión, a mediados del siglo pasado, cuando a los avances tecnológicos y científicos, determinados sacerdotes y hombres de religión de dura cerviz los calificaban de "manifestaciones del maligno". Personalmente me parece que después de los últimos sesenta años el maligno debería estar no rojo, sino verde de envidia por los niveles que hemos alcanzado, pudiéndole enseñar más de una y más de dos cosas. En fin, esa es otra historia.

Volvamos a nuestro tema. A lo largo de este artículo procuraré explicar la procedencia, principios y procesos de fabricación de los transistores, base de los circuitos integrados (chips) en los que algunos tratan de encontrar "hombrecillos verdes".

Aunque las primeras propiedades de los semiconductores, estudiadas por Faraday y Becquerel, se remontan a los años 1833 y 1839, solamente a comienzos de este siglo se empiezan a estudiar las aplicaciones electrónicas de éstos. En 1923, Schotlky publicó una teoría sobre los rectificadores, mas hasta la segunda guerra mundial (1939 - 1945) no se utilizaron. Aunque durante este periodo se les dio un gran impulso, fue en 1948 cuando Brattain y Bardeen, trabajando en los laboratorios Bell Telephone de los EE.UU., descubrieron el transistor de puntas de contacto. En 1949, en los laboratorios Schockley se desarrolló el primer transistor de unión y, a partir de esta fecha, se desarrollan con una gran profusión. En la actualidad hay muchos tipos, para muy variadas aplicaciones: Diodos, Túnel, Tiristores, Diacs, Triacs, Transistores MOS, MOS-FET, BJT, etc.).

Algunos de los motivos, por los cuales se han desarrollado con tan gran rapidez los componentes en estado sólido (semiconductores), frente a las válvulas de vacío que les precedieron son los siguientes: 
-No requieren vacío (obvio).

-Tienen mayor rigidez mecánica (si se caen no se rompen).

-Necesitan tensiones de polarización menores.

-Disipan menos potencia (no tienen caldeos de filamentos, simplificando los circuitos).

-Tienen mayor duración (unas 5000 horas la válvula, frente a 9000 horas del semiconductor).

Aunque también presentan los inconvenientes que, a continuación, se comentan, subsanables, no obstante, a corto - medio plazo:

-Dificultad de manejo de grandes potencias.

-Se dañan por sobrecargas de tensión o corrientes.

-Son muy sensibles a los cambios de temperatura y a las radiaciones.

\section{El material semiconductor}

En la mayoría de las sustancias sólidas naturales, como consecuencia de la peculiar interacción de sus átomos durante la solidificación, éstos se ordenan formando planos en distintas direcciones que dan, como resultado, una figura poliédrica. Esta estructura recibe el nombre de cristal y es característica para cada sustancia, pues debido a que los ángulos formados por caras contiguas se mantienen constantes, todos sus cristales resultan figuras semejantes: 


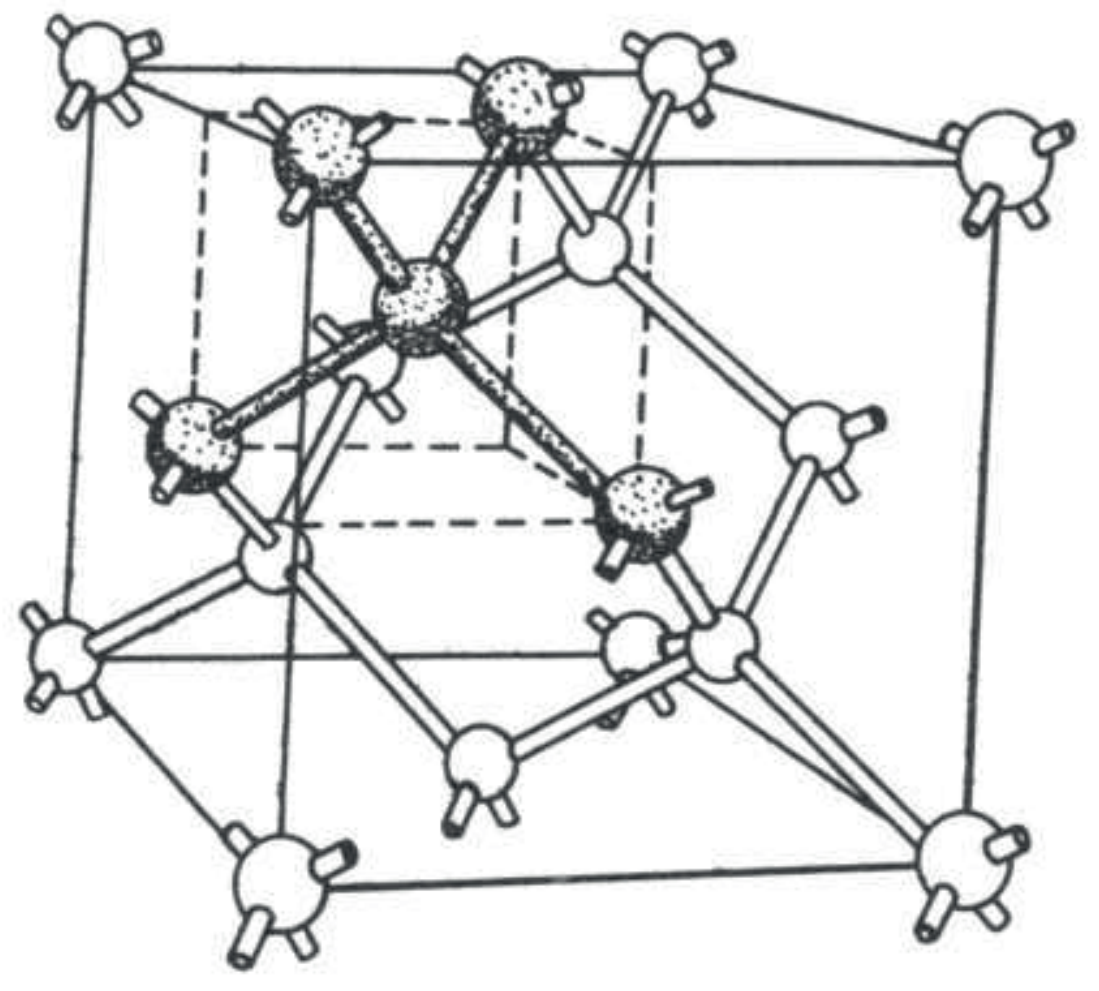

Las interacciones entre átomos son de tres géneros y dan lugar a las tres clases de enlace: Iónico, Covalente y Metálico. Los tres son de mucha importancia; los dos primeros por ser los que actúan en los compuestos químicos, y el último, por sus propiedades, que caracterizan a los metales, de entre las cuales la más importante es la conductividad. Para el caso que estamos tratando en el presente artículo, nos basta con conocer el enlace covalente.

Este enlace se caracteriza porque los electrones de valencia son compartidos dos a dos por los átomos colindantes; esto es, cada átomo aporta un electrón y esta pareja, formando un todo coordinado, gira alrededor de los dos átomos. A continuación se representa la estructura cristalina del $\mathrm{Ge}$, en la que se ven cuatro átomos de este material con sus cuatro electrones de valencia en su capa externa de manera esquemática, donde aparecen cuatro enlaces covalentes: 

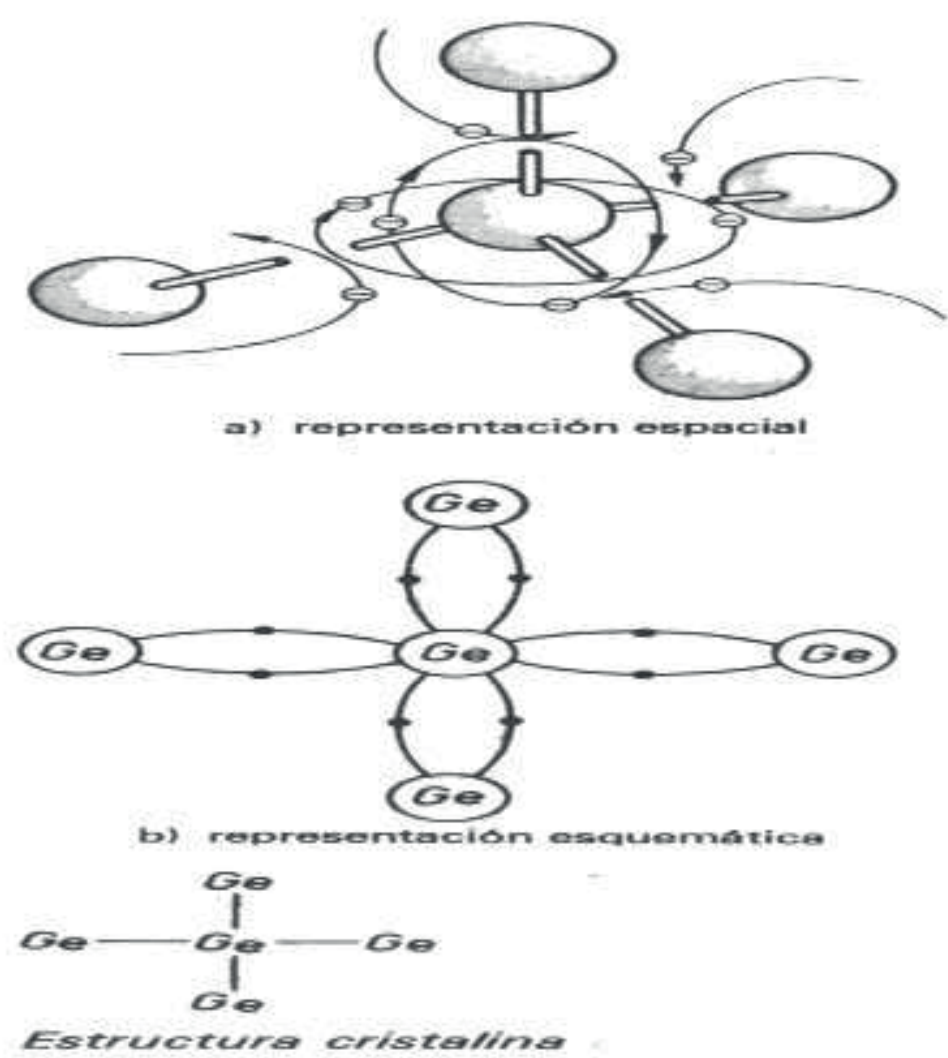

Se sabe que los electrones orbitan en una determinada capa, dependiendo de su energía. Además también sabemos que hay zonas, en las cuales los electrones se ven sometidos a la influencia de varios núcleos estando semilibres. Esto da lugar a definir unos nuevos conceptos, que se llaman bandas de energía, que son las regiones, en las que los electrones tienen una misma energía:

Banda saturada: Es la zona más próxima al núcleo que, como se sabe, contiene el número máximo de electrones admisibles.

Banda de valencia: Son las zonas en las que los electrones son semilibres (recuérdese que, en el enlace covalente, los electrones orbitan alrededor de los dos átomos. 
Banda de conducción: En general, no todos los electrones de la banda de valencia pueden moverse por el cuerpo, así que se define esta nueva banda y es por la que circulan los electrones que tienen suficiente energía para ello.

Bandas prohibidas: Entre las diferentes bandas existen unas zonas en las cuales no hay ningún electrón (téngase en cuenta que los electrones se sitúan en capas correspondientes a niveles cuánticos enteros de energía). A estas zonas se les llama bandas prohibidas.

Atendiendo a estos conceptos de bandas de energía, se puede obtener una definición de conductor eléctrico. Así, se dirá que es conductor aquel material en el que la banda de conducción se solapa con la de valencia. Un aislador, por el contrario, tiene entre la banda de valencia y la de conducción una banda prohibida de varios eV (eV: electrón voltio, es decir, energía adquirida por un electrón al ser acelerado mediante una diferencia de potencial de un voltio). Supóngase un metal conductor, a una determinada temperatura. En la banda de conducción existirán algunos electrones. $\mathrm{Si}$, por el contrario, se tiene un material aislante, a esa misma temperatura no existirá ningún electrón en la banda de conducción y sí en la de valencia. Por lo tanto, para conseguir llegar a la banda de conducción, hay que proporcionar energía a los electrones de la banda de valencia. 


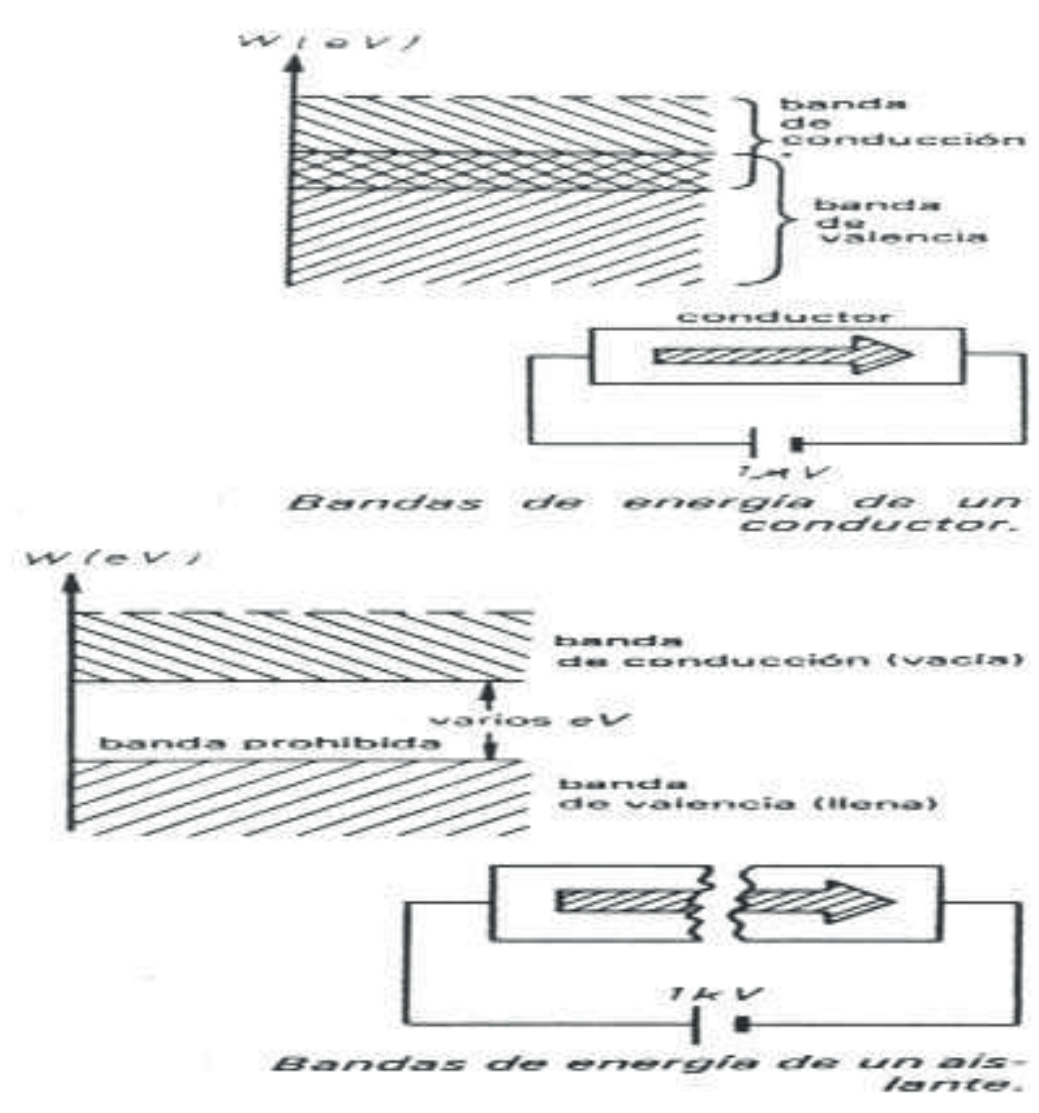

Si la banda prohibida es muy ancha, será necesaria mucha energía; por lo cual, cuanto más ancha sea la banda prohibida, más aislante es el material. Si, por el contrario, la banda prohibida no existe, la de conducción se superpone con la de valencia y el material será un buen conductor. Entre ambos tipos de material existen otros que amplían nuestra clasificación: los semiconductores. Como la misma palabra indica, no son muy buenos conductores, pero tampoco son aislantes, por lo que su resistividad es intermedia, y su banda prohibida no es como en el caso de la aislante de unos eV, sino sólo de, aproximadamente $1 \mathrm{eV}$. 


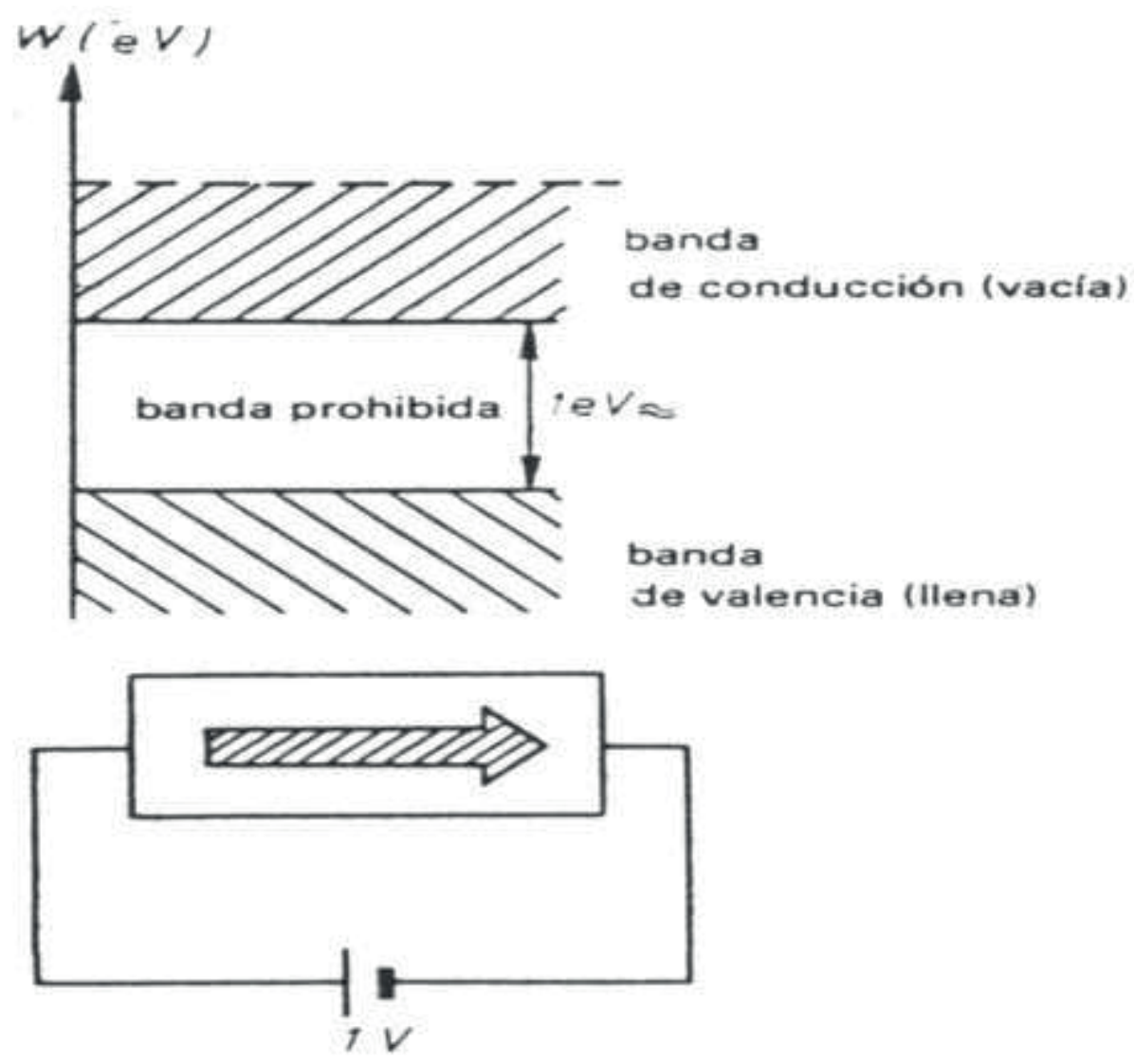

Por consiguiente, los semiconductores se caracterizan por tener una banda prohibida, entre la de conducción y la de valencia, pero no muy ancha. Ello marca la diferencia esencial con los conductores, que no la tienen, y con los aisladores, que al ser tan ancha no pueden saltar las cargas que producen la conducción. Por otra parte, los elementos semiconductores tienen cuatro electrones en su última capa, lo que hace que su cristalización se realice por enlaces covalentes. Esta clase de enlace posibilita el salto de los electrones compartidos a la banda de conducción para las aplicaciones posteriores.

Resumiendo:

-Acabamos de decir que los semiconductores son materiales que unen sus átomos por enlace covalente, 
-Se sabe también que, para que haya conducción, es necesario que existan electrones libres, esto es, que se desplacen electrones por el material, sin que les afecten los núcleos de los átomos,

-Por tanto, habrá que hacer saltar los electrones de los enlaces covalentes de la banda de valencia a la banda de conducción.

A temperatura ambiente, los átomos de un semiconductor no suelen tener todos los enlaces covalentes saturados; esto hace que existan algunos electrones en la banda de conducción que han tenido suficiente energía térmica para liberarse de la atracción de su núcleo. Estos electrones son muy pocos, debido a la gran estabilidad del enlace covalente. Con esto, debemos introducir un nuevo concepto que, a primera vista, puede parecer un artificio: el elemento en la conducción denominado como hueco. Cómo antes se ha dicho, los átomos se unen en todo el cristal mediante enlaces covalentes y, por tanto, si un electrón (de los dos compartidos de un enlace) es extraído del enlace, quedará una vacante o hueco, que podrá ser llenado por otros electrones, que se inyecten en el material. Se dice, por tanto, que en la conducción de los semiconductores interviene el par electrón-hueco, a saber, como se muestra en la siguiente figura: 


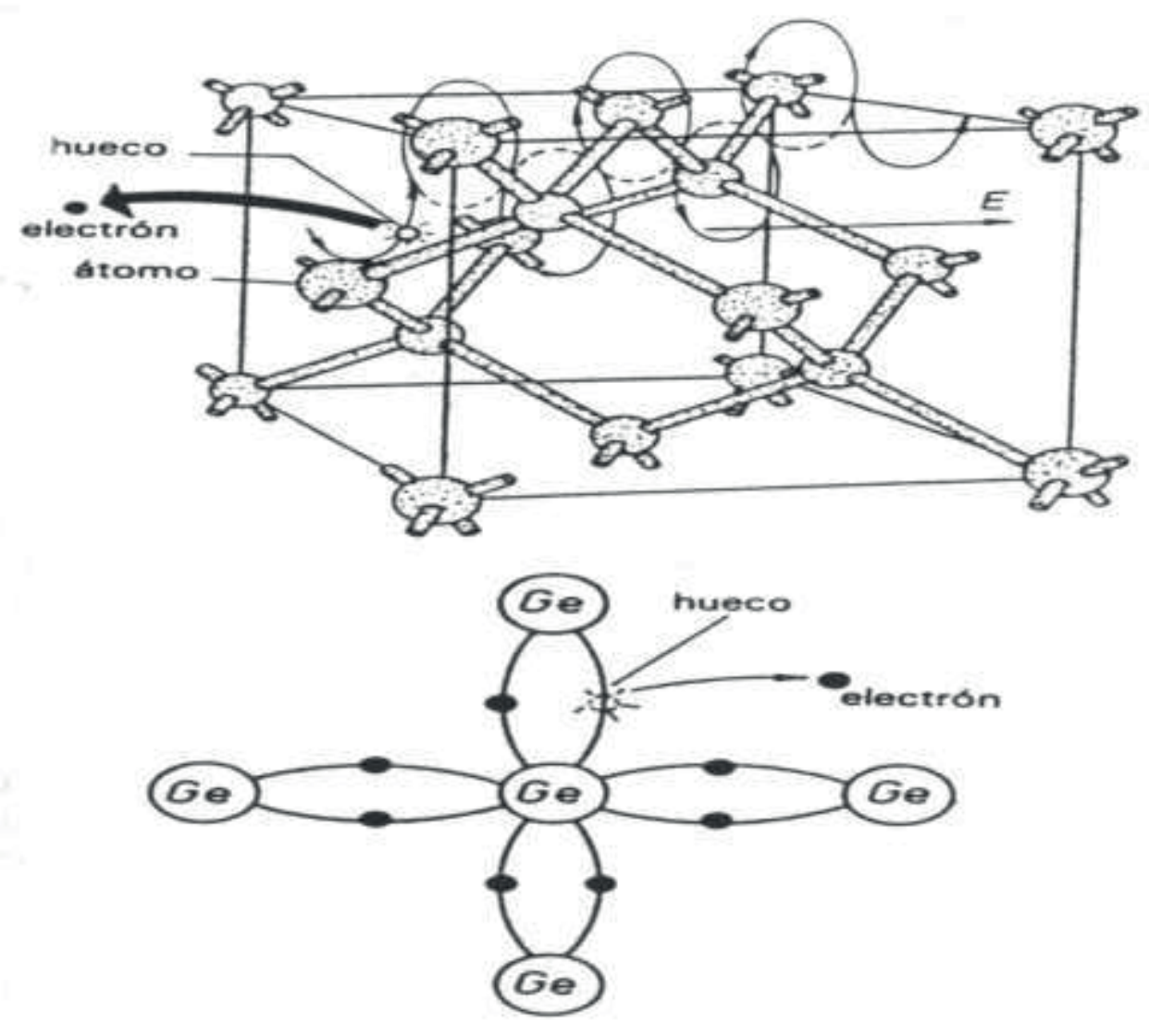

Así las cosas, se define como hueco la ausencia de carga en una posición del átomo en que debería existir. A esta ausencia de carga se le da, por convenio, el signo positivo, como consecuencia de que el átomo, sobre el que orbita, se ha quedado con un protón más en su núcleo que electrones tiene en la corteza (recuérdese que el hueco aparece por ausencia de un electrón del enlace covalente). En la anterior figura, se observa cómo, sometido un cristal de germanio a la acción de un campo eléctrico E, los huecos se desplazan en el sentido del campo y los electrones en el contrario, lo cual corrobora la idea afirmada de que los huecos tienen carga positiva. A fin de cuentas, podemos afirmar que la conducción en los semiconductores se realiza por portadores de carga, pares electrón-hueco, de los que el primero es negativo y el segundo será positivo, sin "buscarle más pies al gato". 


\section{Clasificación de los semiconductores}

Los semiconductores más utilizados son el germanio y el silicio. Ahora bien, como se sabe, purificar un material al cien por cien requiere procesos muy costosos, lo que hace que los materiales que se usan contengan muchas impurezas. Por la cantidad de éstas en su composición, se pueden clasificar los semiconductores en:

a) Semiconductores intrínsecos: Son los que prácticamente carecen de impurezas; un átomo de impureza por cada 1011 átomos de semiconductor. En estos semiconductores, que se pueden considerar casi puros, la conducción se realiza por pares electrón-hueco, producidos por generación térmica, de modo que cuanto mayor es el calor, mayor es la cantidad de portadores de carga libre y menor su resistividad. Debido a esta clase de conducción, estos semiconductores suelen emplearse como elementos sensibles a la temperatura, ya que, a bajas temperaturas, hay pocos pares electrón-hueco y se comportan como materiales casi aislantes, pues todos los enlaces están completos y no hay candidatos a ser portadores de carga. Por el contrario, cuanto mayor es la temperatura, mayor es el número de pares electrón-hueco y, por consiguiente, la resistividad disminuye.

b) Semiconductores extrínsecos: Son los que poseen un átomo de impureza por cada 107 átomos de semiconductor. Además, estos átomos de impureza, más numerosos que los del semiconductor intrínseco, suelen tener tres o cinco electrones de valencia, a fin de que les sobre o les falte un electrón para completar los enlaces covalentes. Al tener portadores independientes de la generación térmica, la resistividad de éstos semiconductores es menor que la de los intrínsecos. Su conductividad será mayor cuanto mayor sea el número de portadores libres, y, por tanto, aumentará con el número de impurezas. La aplicación de este tipo de semiconductores da lugar a los dispositivos más 
importantes, transistores, diodos etc., que se basan en el control de los portadores de carga, electrones o huecos. Como hemos mencionado, los átomos de las impurezas suelen tener tres o cinco electrones de valencia, lo que permite subdividir estos semiconductores en dos tipos de gran importancia:

Tipo N: Si en una estructura cristalina se introduce un átomo que tenga cinco electrones de valencia (por ejemplo As, Si ó Sb), cuatro de estos electrones se unirán con otros cuatro, uno de cada uno de los átomos cercanos y formarán los cuatro enlaces covalentes. Mas el quinto electrón quedará libre y podrá extraerse, con relativa facilidad, de la acción de su núcleo, ya que se encuentra muy cerca de la banda de conducción del semiconductor. A temperatura ambiente $\left(20^{\circ} \mathrm{C}\right)$, el electrón se encuentra en la banda de conducción y, por tanto, podrá actuar como portador de carga negativa.
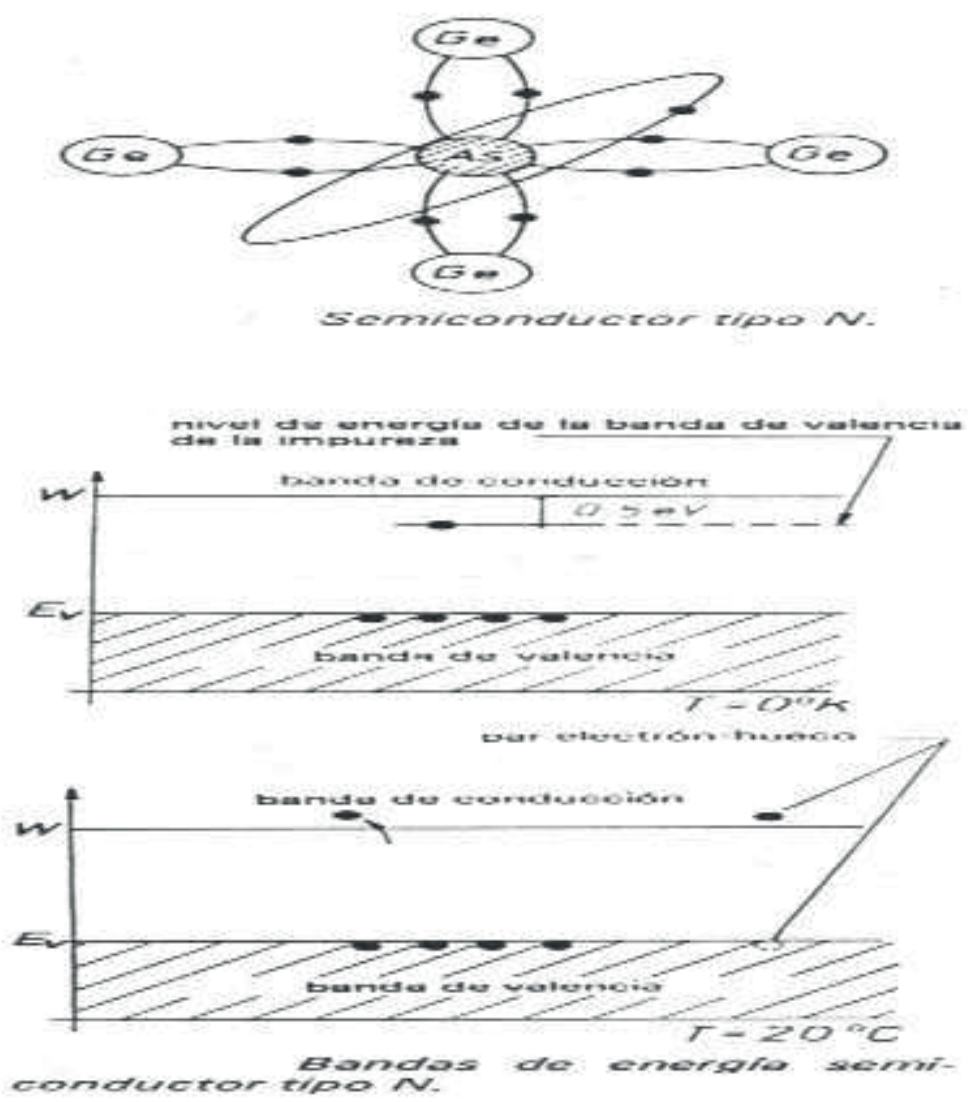
Si el número de impurezas es grande, el número de electrones, libres por este motivo, a temperatura ambiente, será superior al número de pares electrón-hueco producidos por generación térmica. De esta manera, se pueden clasificar los portadores de carga en mayoritarios y minoritarios. Por ello, a los átomos de impurezas de estos semiconductores se les llama átomos donadores, porque proporcionan electrones y quedan cargados positivamente (iones + ) debido a su pérdida de electrones.

Tipo P: En el apartado anterior vimos que, al introducir átomos de impurezas que tenían cinco electrones de valencia, se constituía un semiconductor extrínseco de tipo N. Si, por el contrario, los átomos de impureza son de tres electrones de valencia (por ejemplo In, Be ó Al), los cuatro átomos de semiconductor no podrán compartir sus electrones con el átomo de impureza ya que, utilizando sus tres electrones, tan sólo se podrán formar tres enlaces covalentes, quedando el átomo semiconductor del cuarto enlace con un hueco en él, que podrá ser llenado con los electrones de los átomos próximos. A temperatura ambiente, el hueco ya no se encontrará localizado en el átomo de impureza, sino que será libre en el cristal y se utilizará como portador de carga en la conducción. 


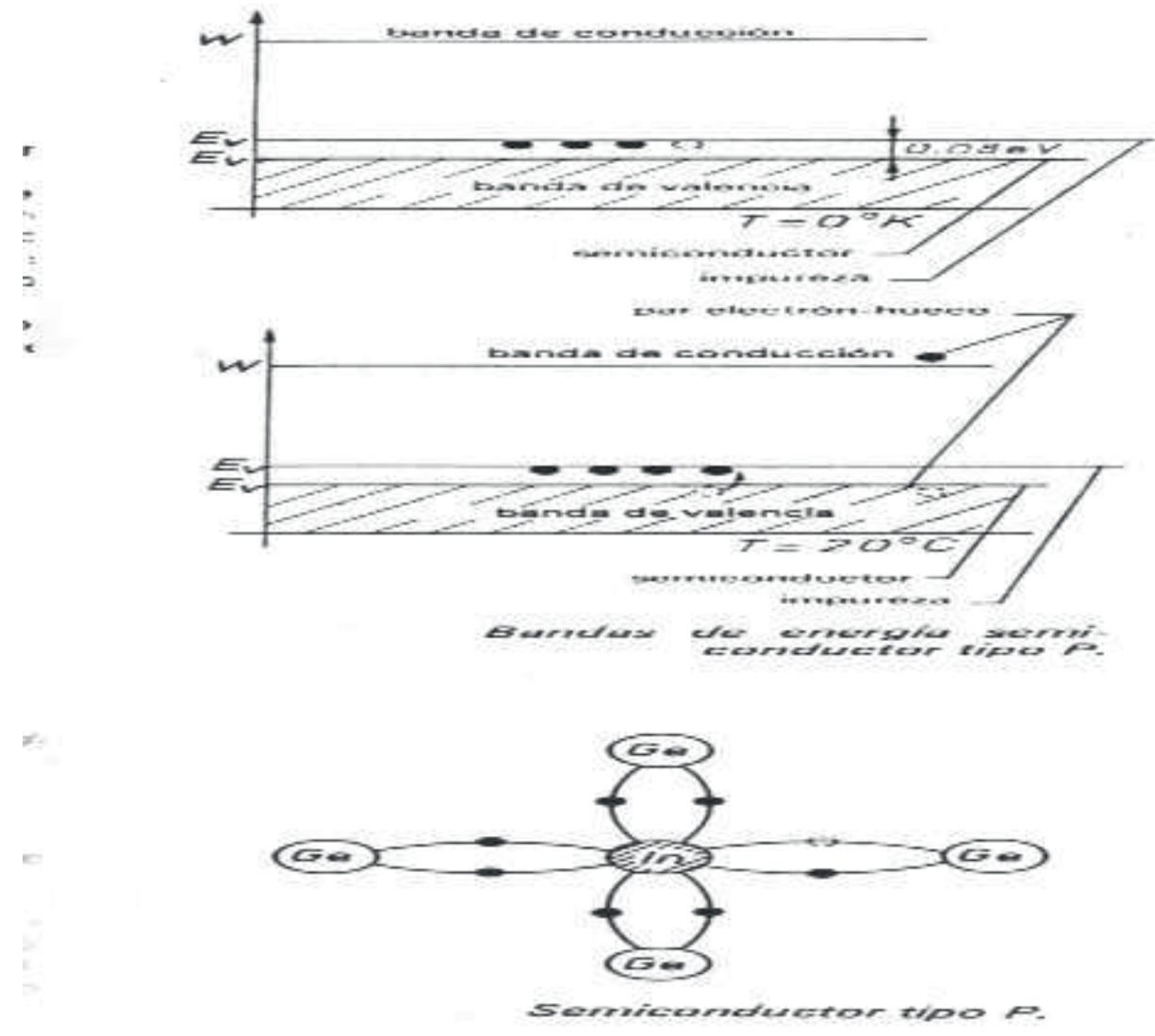

$\mathrm{Al}$ igual que en los semiconductores tipo $\mathrm{N}$, cuando el número de impurezas es grande, existirán, a temperatura ambiente, más portadores huecos, que pares electrón-hueco. Por ello, a los átomos de impureza se les llama aceptadores, porque reciben electrones de los átomos del semiconductor para proporcionar huecos como portadores de carga y quedan cargados negativamente (iones -).

\section{El diodo}

A partir de estos semiconductores extrínsecos, como ya adelantamos, se implementan los dispositivos electrónicos de estado sólido que conocemos. El diodo semiconductor es conocido de muy antiguo; basta recordar el cristal de galena, utilizado en los primeros aparatos de radio. Posteriormente, fue desbancado por el diodo de vacío con la importancia que adquirieron las válvulas de emisión 
termoiónica, sin embargo, fue a partir de 1920 cuando se empezó a utilizar el rectificador de selenio y de óxido de cobre. Aquel año, como ya se ha dicho, se publica una teoría sobre los rectificadores y se vienen utilizando en este campo con gran profusión hasta hace pocos años, sin intervención de "mano, tentáculos, garras o lo que sea de naturaleza extraterrestre". Con el desarrollo de la electrónica digital o lógica (electrónica para computadoras y mandos industriales) toman tal auge los diodos semiconductores que, en la actualidad, puede decirse que el campo de aplicación de los semiconductores es prácticamente ilimitado.

Si un semiconductor, intrínseco o extrínseco, se conecta a un potencial eléctrico, sólo se conseguirá que, en función de las impurezas, el material tenga más o menos conductividad y que, por consiguiente, circule más o menos corriente. Si se unen dos semiconductores extrínsecos, uno de tipo $\mathrm{N}$ y otro de tipo $\mathrm{P}$, se habrá conseguido un diodo semiconductor. Hay que observar que polarizar una zona positivamente es conectarla al potencial positivo de la pila o fuente de alimentación (F.A.); hacerlo negativamente, por el contrario, es polarizar la zona (parte conectada) con el polo negativo de la pila o F.A., es decir: 


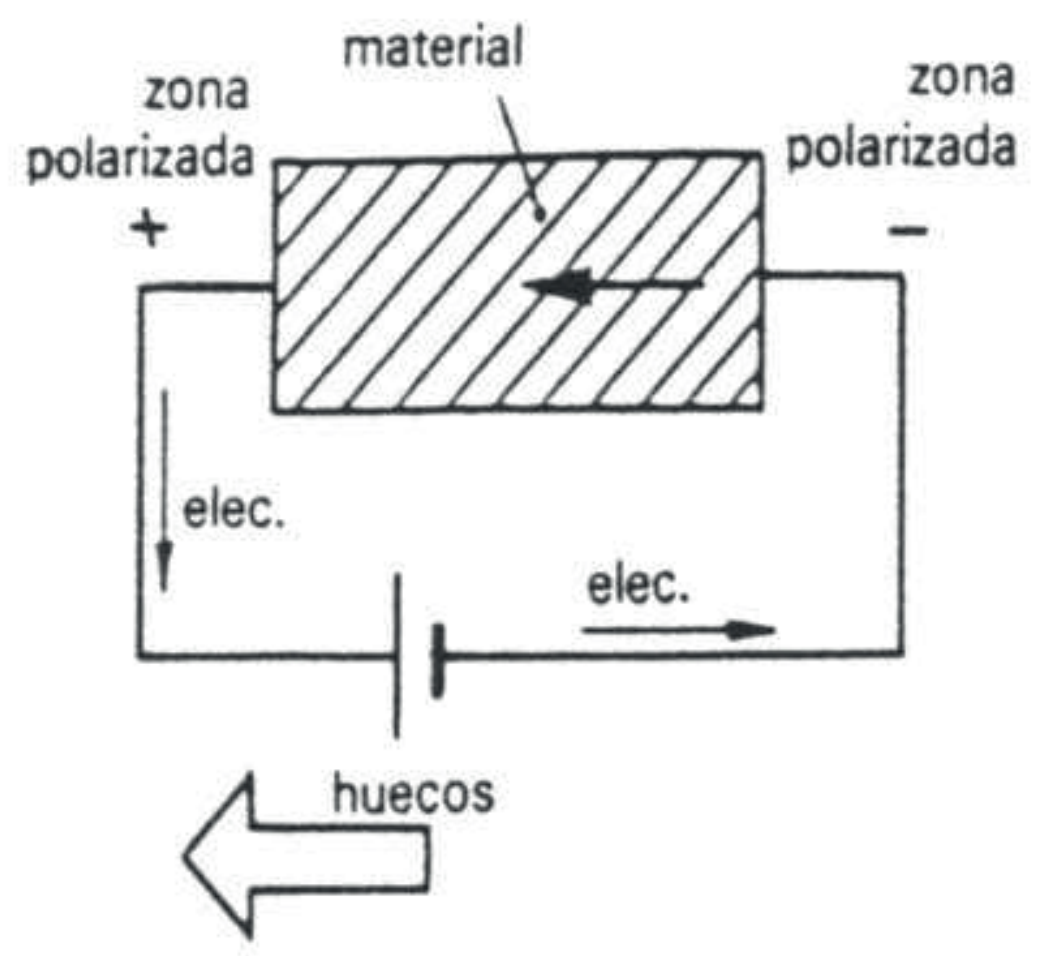

De esta forma, si se unen dos cristales, uno $\mathrm{N}$ y otro $\mathrm{P}$ se observará que, al polarizarlos, se introducen electrones en la zona $\mathrm{P}$, en la que hay huecos, y se extraen los electrones de la zona $\mathrm{N}$, donde hay electrones, con lo que llegará un momento en que no existirán portadores de carga en el material y casi se hará nula la corriente. Si, por el contrario, se polarizan en sentido inverso resultará que en la zona $\mathrm{N}$ se inyectan electrones $\mathrm{y}$, en la $\mathrm{P}$ se disminuyen, con lo que aumentará en ambas el número de portadores de carga y, por tanto, existirá la conducción, a saber: 

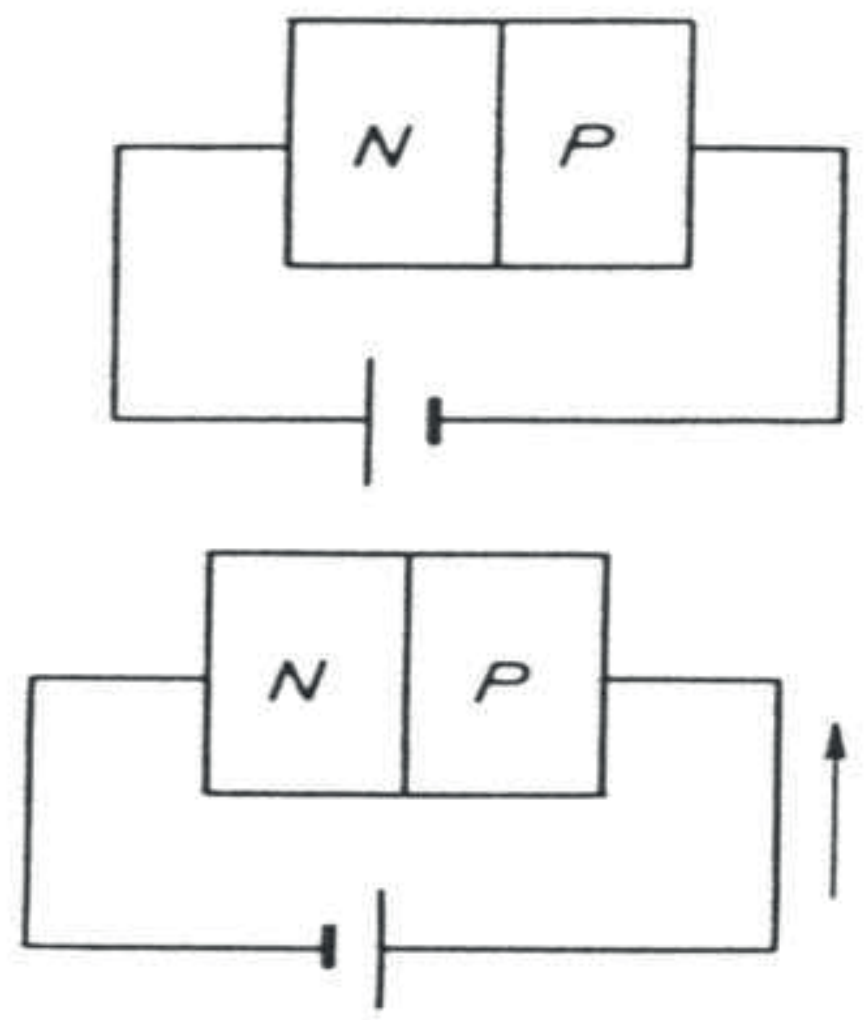

La zona de contacto entre los dos cristales, tipos $\mathrm{N}$ y P, se denomina unión. Se podría pensar que la unión se puede formar fácilmente pegando simplemente los cristales, pero no es así, ya que, no sólo tienen que estar en contacto, sino que, además, deben tener contacto eléctrico. Hay varios métodos para formar la unión, a saber:

-Por aleación.

-Por extracción.

-Por difusión.

Básicamente, producir la unión es lo mismo que intentar mantener la estructura cristalina en la frontera y que la estructura del cristal P continúe con la del $\mathrm{N}$ y viceversa: 


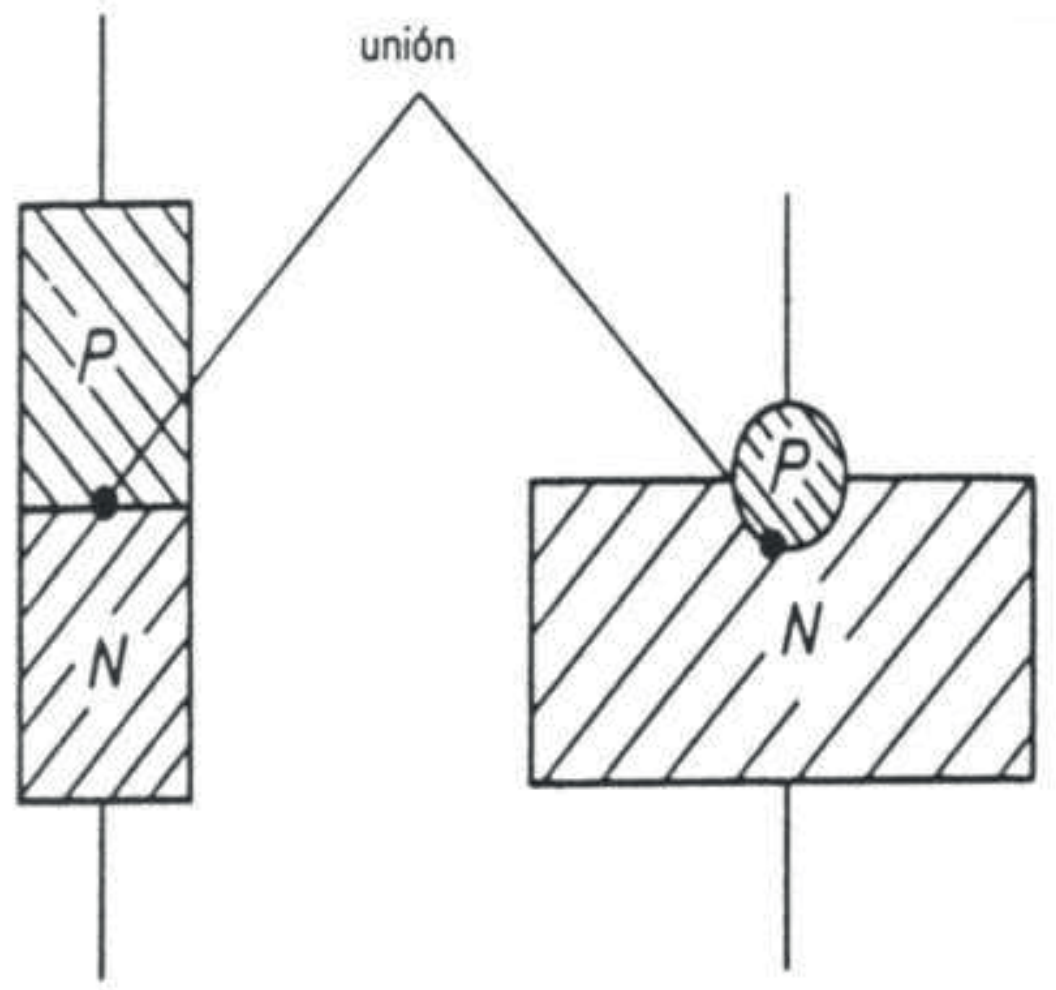

Hay que recordar que el cristal tipo $\mathrm{N}$ tendrá electrones libres (tantos como átomos de impureza) y, por tanto, igual número de cationes (átomos donadores). De la misma forma, en el cristal tipo P habrá huecos y aniones (aceptadores). Puede verse que ambos cristales tienen carga neutra: 


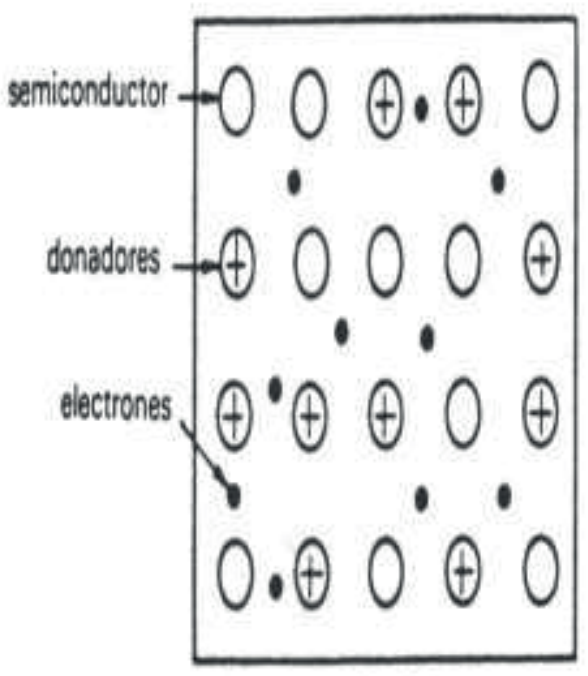

tipo N

a

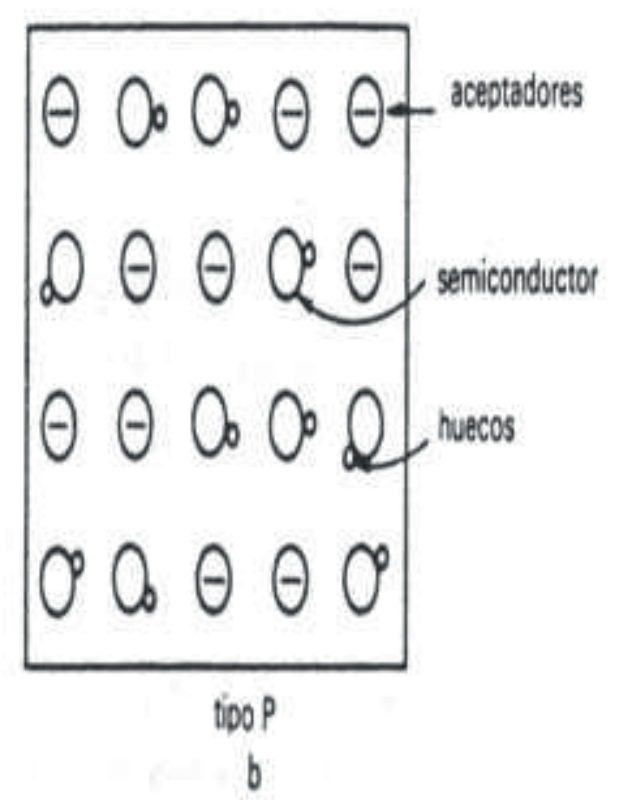

b

\section{Composición electrica de los cristales.}

Si se efectúa la unión, los electrones del material N pasarán al P para llenar los huecos, creando una zona en la cual no existen portadores de carga. Esta atracción, entre los huecos y los electrones, continúa hasta que los iones de la red cristalina (los átomos de impurezas) equilibran la atracción entre los portadores. 


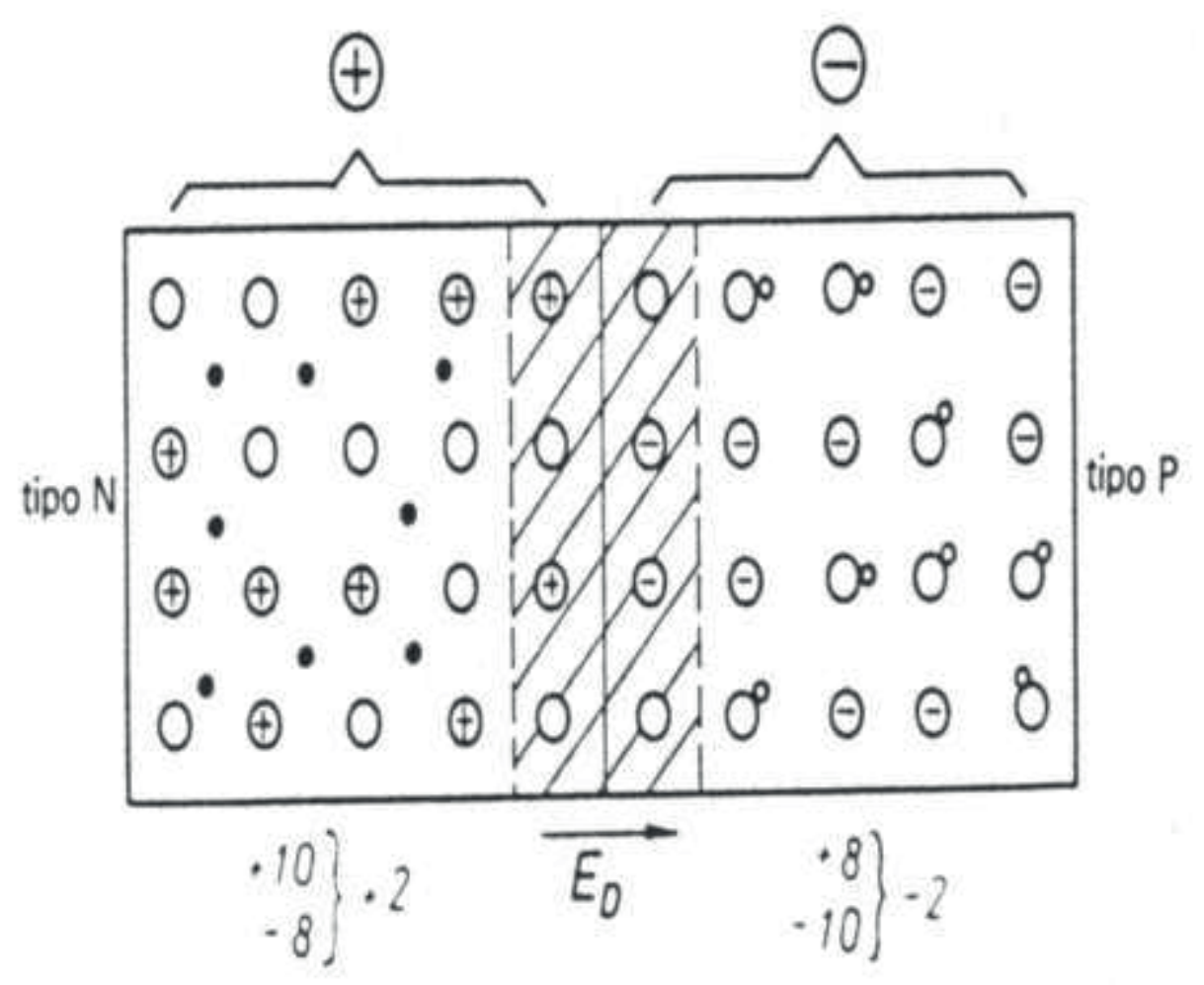

Supóngase ahora un electrón en la zona N. Éste se ve atraído por los huecos de la zona $\mathrm{P}$ pero, en la zona de difusión, ya existen algunos átomos aniones y éstos rechazarán al electrón. Si la repulsión de los aniones es mayor que la atracción ejercida por los cationes de la misma zona, el electrón no cruzará la zona de difusión y habrá terminado la recombinación; esta zona, desprovista de carga, suele llamarse zona de difusión. Como consecuencia de la difusión de los portadores de carga hacia el cristal contrario, los electrones de la zona $\mathrm{N}$ pasan a ocupar los huecos de la zona $\mathrm{P}$, produciéndose una zona en la que no existen portadores de carga. Ya, en las anteriores dos figuras, se veía que la carga neta del diodo era nula. Después de formada la unión y como consecuencia de la desaparición de estos portadores de corriente mayoritarios, los semiconductores $\mathrm{P}$ y $\mathrm{N}$ dejan de ser eléctricamente neutros. En el semiconductor P hay una mayor concentración de cargas eléctricas negativas, debido al predominio de iones negativos existentes en la unión; estas cargas no están compensadas ahora, como antes, por los huecos, ya que éstos se han 
recombinado con los electrones que se difundieron desde la zona N. Por análogas razones, el semiconductor $\mathrm{N}$ habrá adquirido una mayor concentración de cargas eléctricas positivas, ya que en él predominan los iones positivos, en la zona cercana a la unión, lo que equivale a que la unión se pueda "suponer" como una pila de unos 0,3 V ó 0,6 V, según sea diodo de germanio o de silicio, respectivamente.

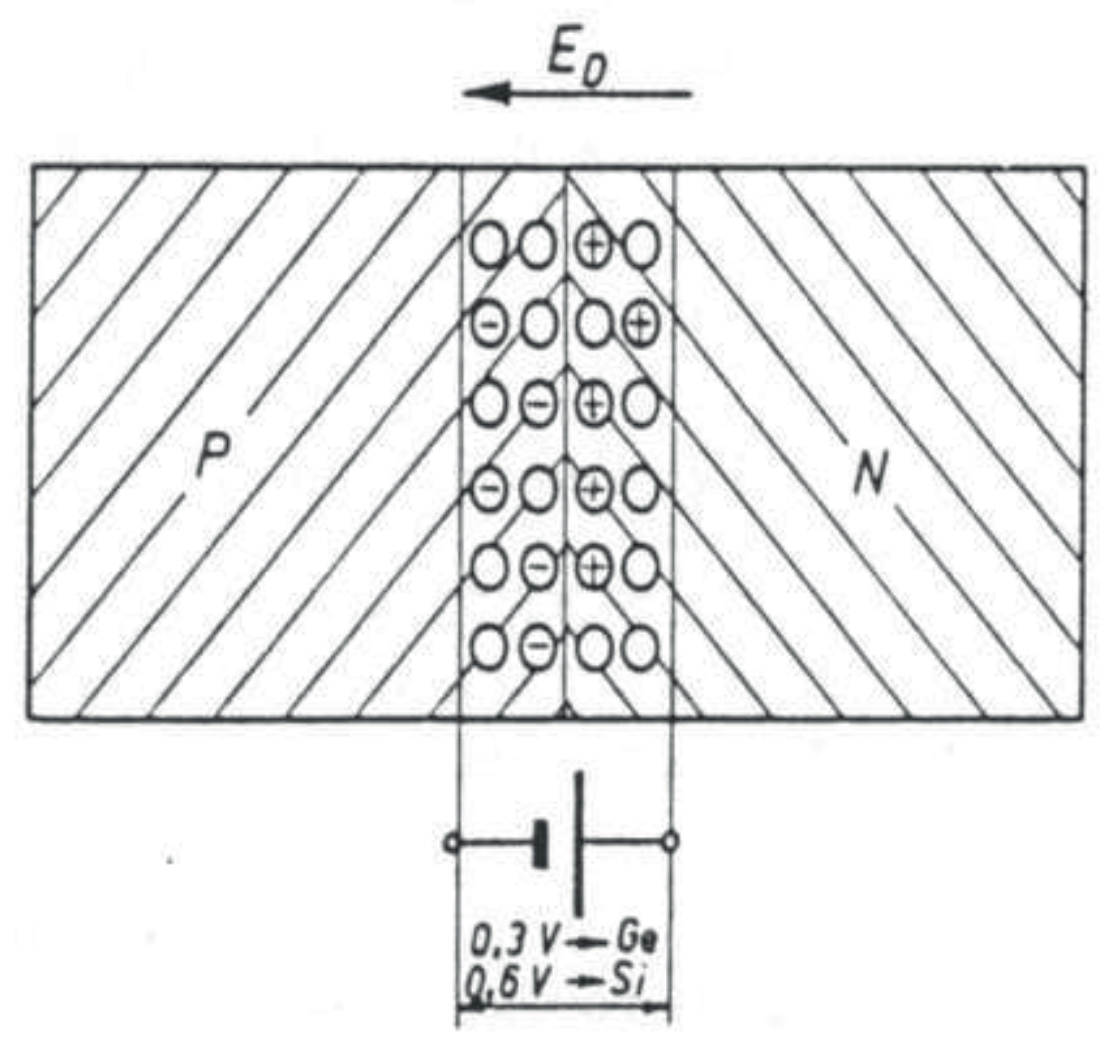

Estas cargas hacen que en la zona se cree un campo eléctrico Eo: 


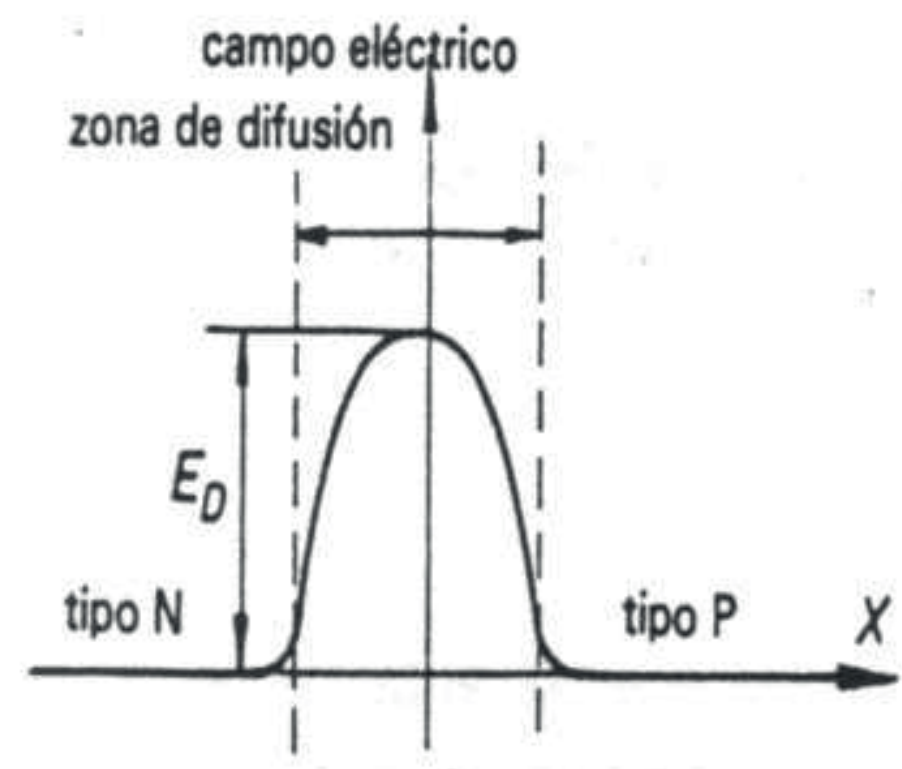

\section{Campo eléctrico interno en la unión PN.}

Este gráfico da una idea del concepto de barrera. Si los electrones de la zona $\mathrm{N}$ tienen suficiente energía, podrán eludir el frenado producido por el campo Eo, saltarán la barrera y pasarán a la zona P; de lo contrario, no habrá conducción, ya que los electrones intentarán saltar la barrera y no lo conseguirán. Si la barrera es muy alta, no habrá ningún portador que tenga suficiente energía para saltarla, y la unión se comportará como un aislador. 


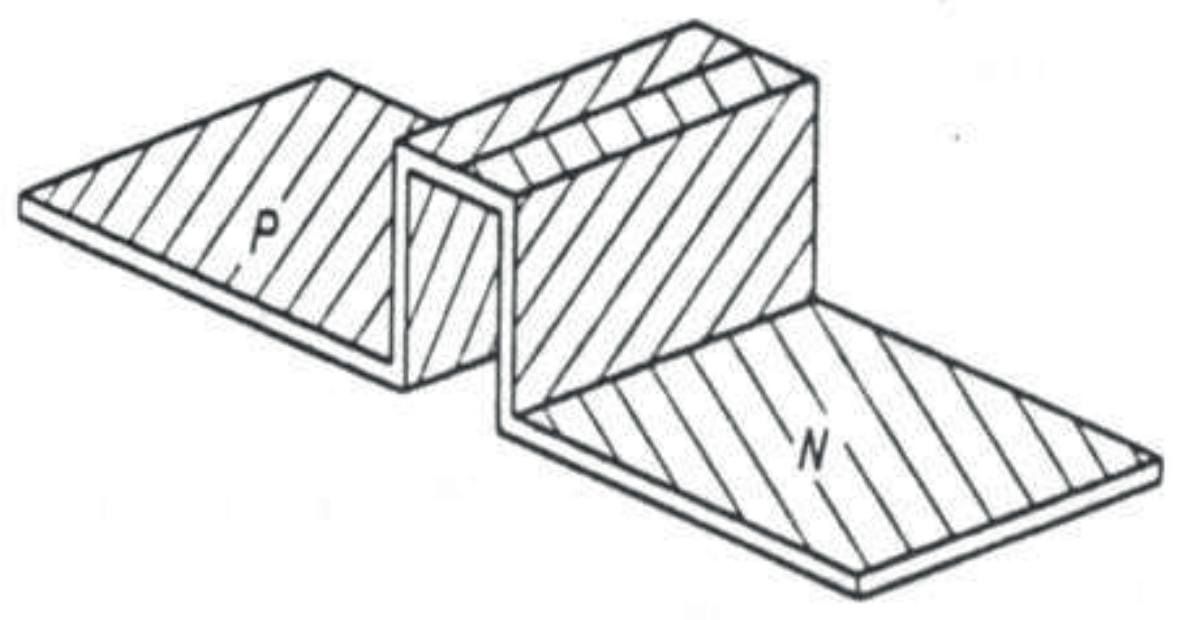

\section{Simil de la barrera de potencial.}

En general, polarizar es aplicar a los extremos de un componente una tensión continua que le mantiene en funcionamiento. De esta forma, polarizar un diodo será hacer que los dos extremos de éste tengan polaridades contrarias. Luego caben dos soluciones, que son: 

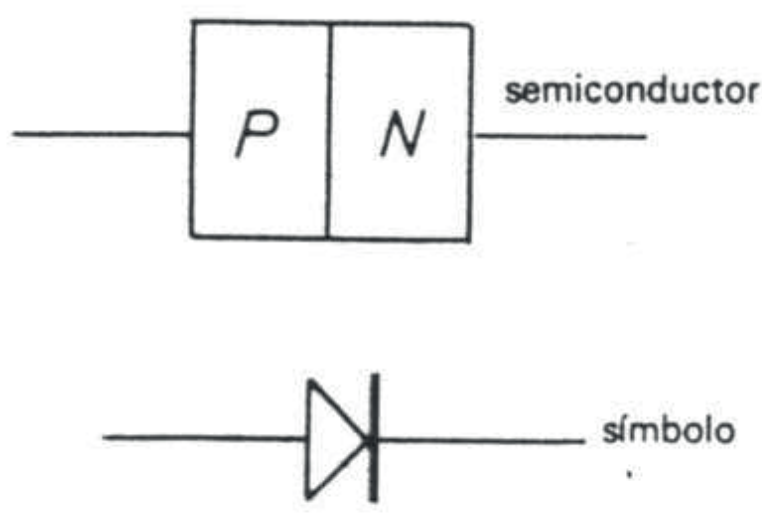

a $十$

circula corriente

$\mathrm{b}-$

no circula t

\section{Polarización: a, directa; \\ b, inversa.}

Se denomina polarización directa, cuando se aplica el polo positivo de la F.A. (fuente de alimentación) a la zona P de la unión y el negativo a la zona N. Con tal conexión, se produce una inyección en las dos zonas de portadores mayoritarios y, como consecuencia, disminuirá la carga neta (las dos cargas) en cada zona, y también el campo eléctrico producido por ellas, con lo que la barrera será más baja y la zona de difusión más estrecha. 


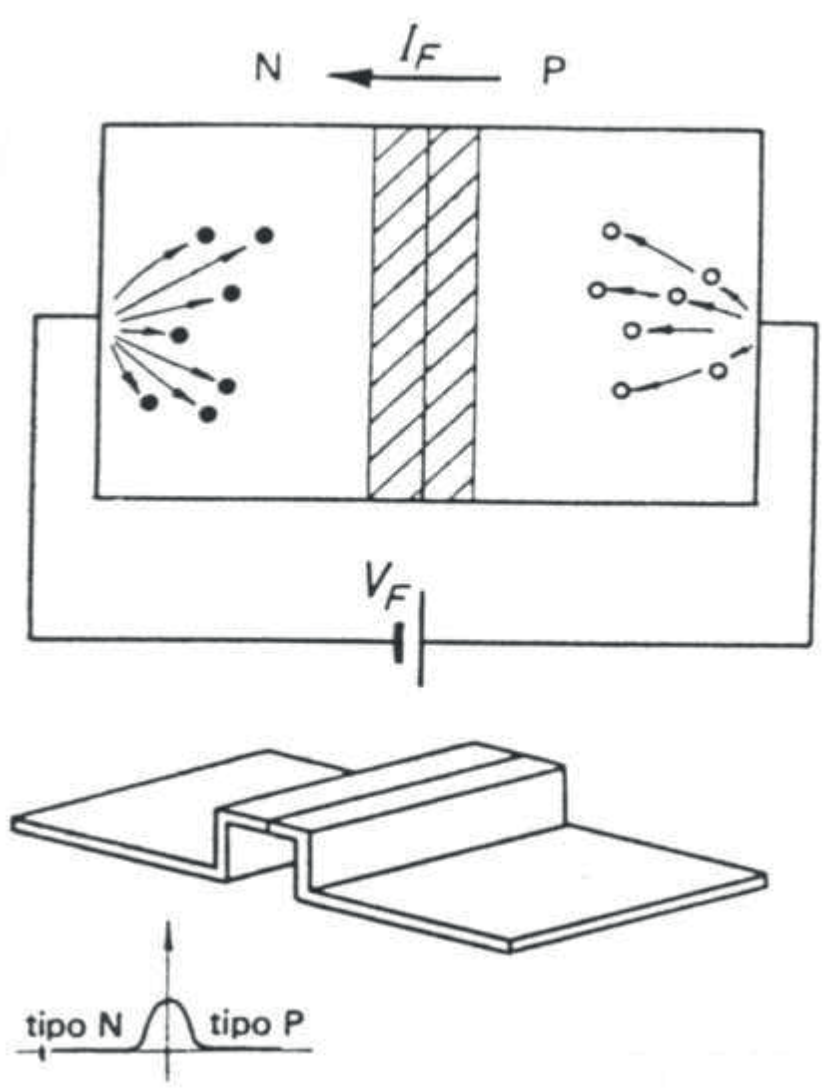

Esta menor altura de la barrera de potencial se traduce en que todos los electrones, tanto los inyectados como los de impurezas, tendrán suficiente energía para atravesarla $\mathrm{y}$, aun siendo pequeña la tensión $\mathrm{V}$ entre bornes, será apreciable la corriente directa. Nótese que se inyectan portadores mayoritarios donde ya los hay, lo que hace que exista una superabundancia y, de esta forma, son más fácilmente atraídos por el borne contrario. Si, ahora, se polariza un diodo semiconductor, según se muestra: 


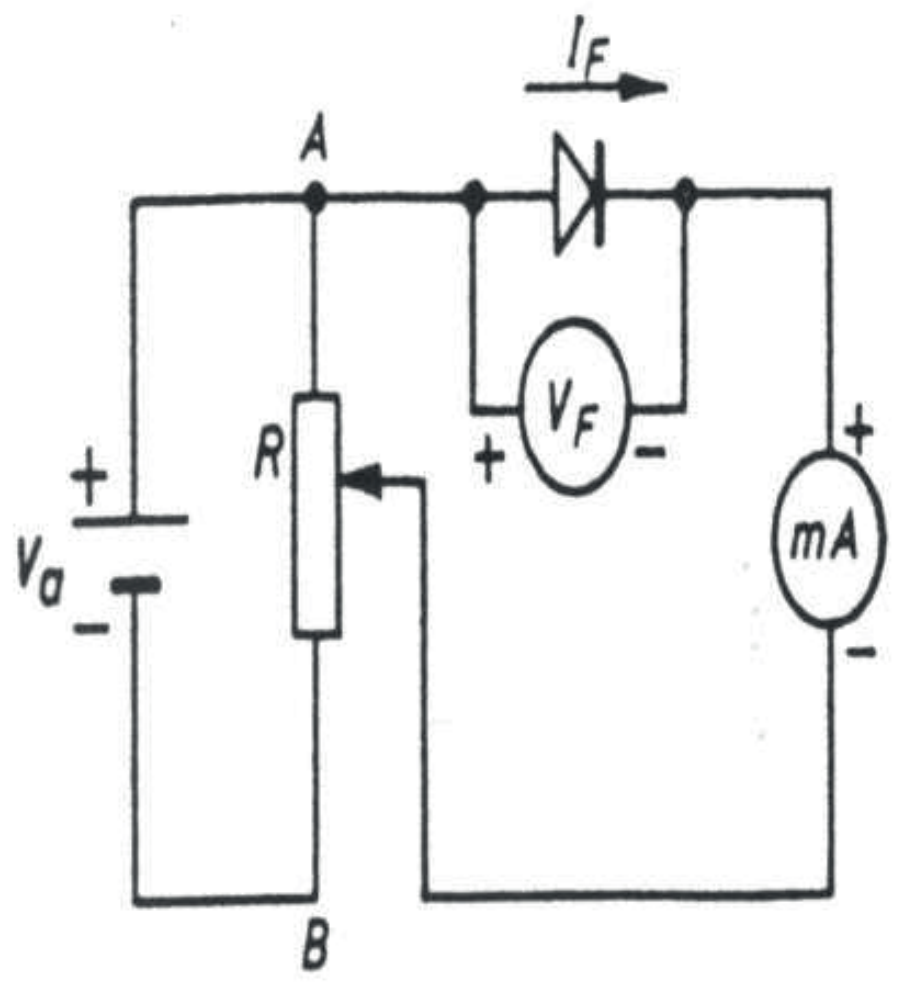

y se efectúan lecturas sucesivas en el voltímetro y microamperímetro, para diferentes posiciones del potenciómetro $\mathrm{R}$, se obtendrá un gráfico semejante al siguiente, donde vemos que, si no hay excitación, la corriente es nula. 


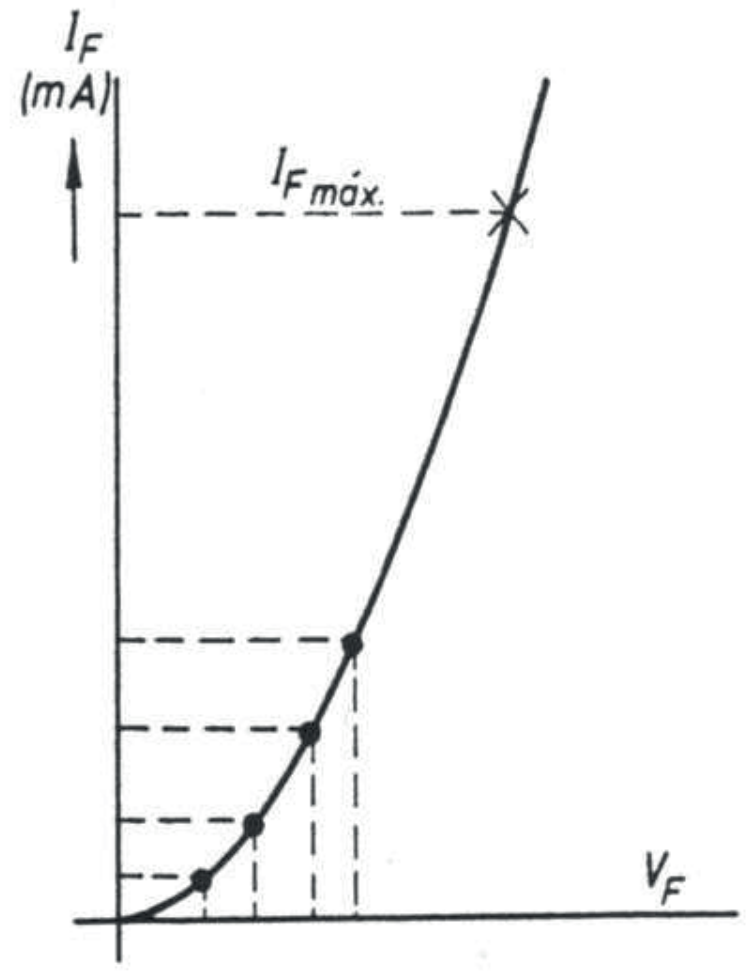

Otra forma de polarización es la inversa, obtenida conectando el polo positivo a la zona $\mathrm{N}$ y el negativo a la zona $\mathrm{P}$, concretamente: 


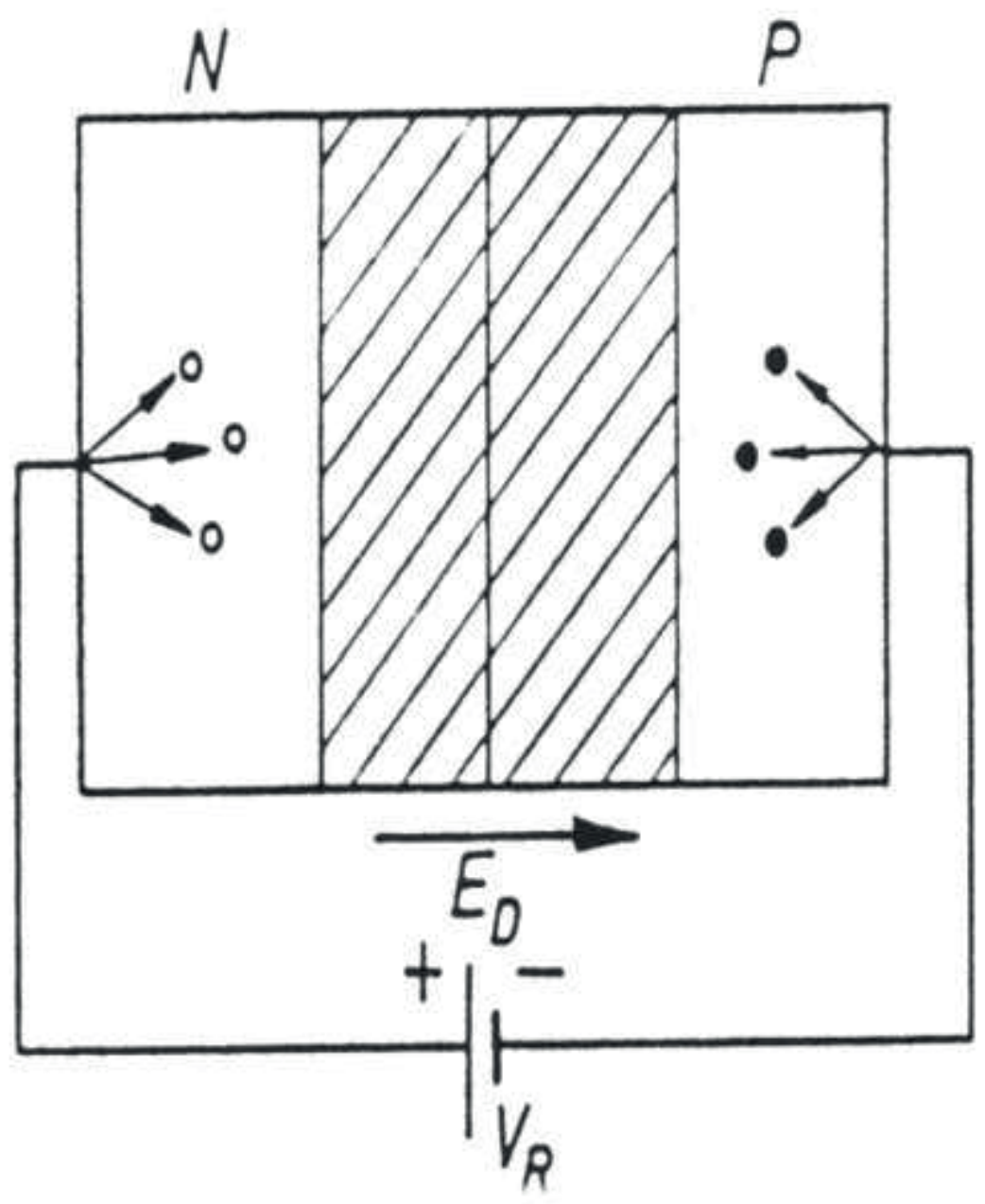

Obviamente, la zona de difusión ha aumentado su anchura, ya que por el borne de la zona $\mathrm{N}$ entrarán huecos $\mathrm{y}$, como las impurezas son electrones, se combinarán, quedando, incluso, algunos que saldrán por el cristal hacia el borne de la batería. De esta forma, se agranda la zona de difusión, porque los portadores mayoritarios son atraídos por la F.A., y la zona desprovista de portadores es más amplia. Como el número de cargas positivas y negativas en la zona de difusión habrá aumentado, también será mayor el campo eléctrico en dicha zona y, por consiguiente, la barrera de potencial será más alta: 


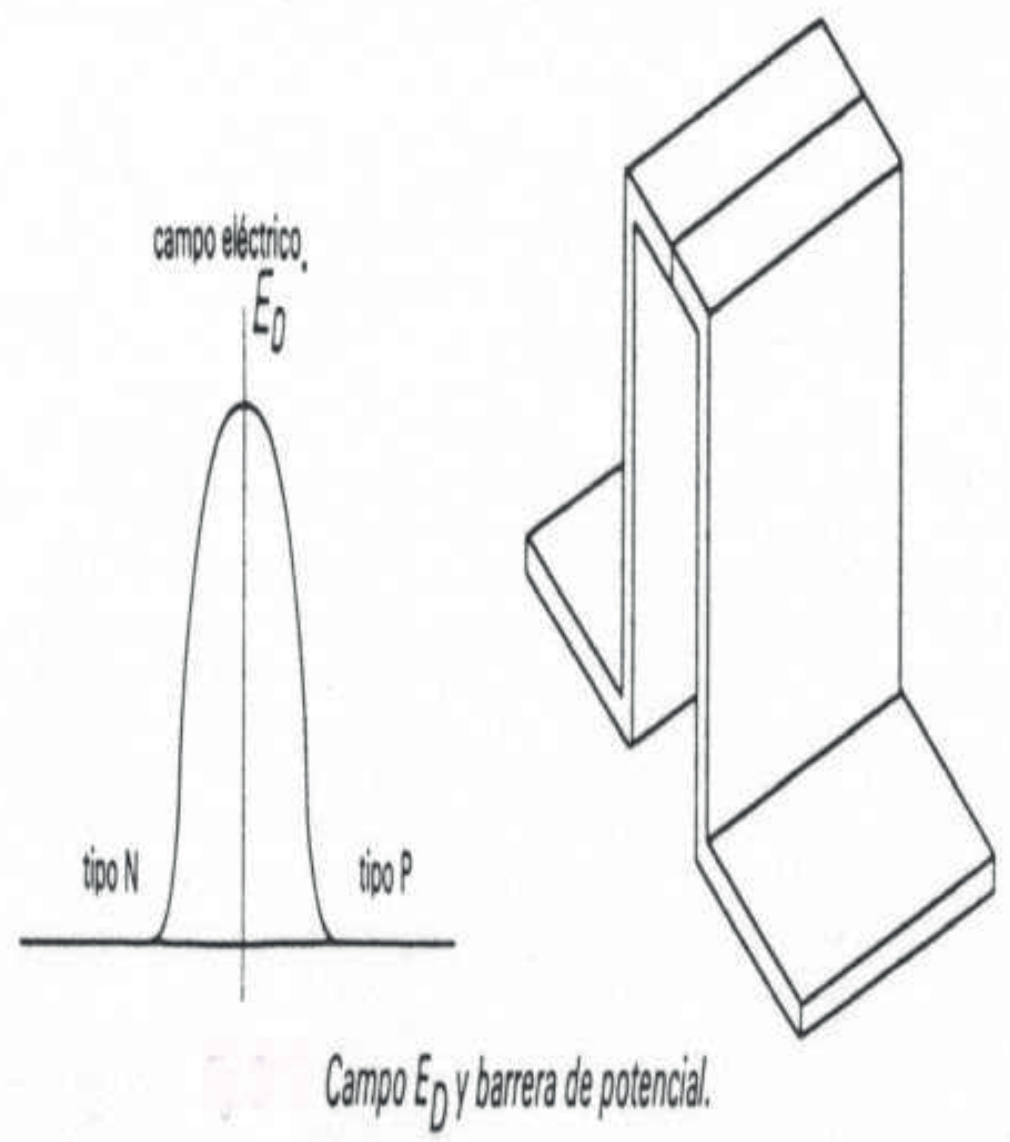

Con una barrera tan alta, será muy raro que haya electrones con suficiente energía para atravesarla, lo que hace prácticamente nula la corriente por el circuito, a saber: 


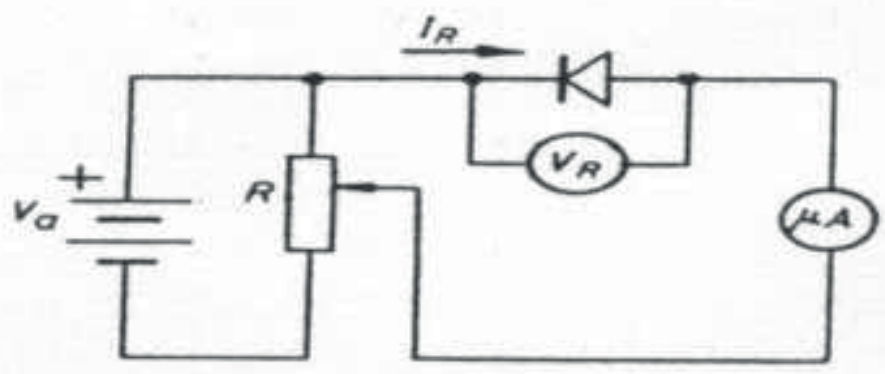

Polarización inversa.

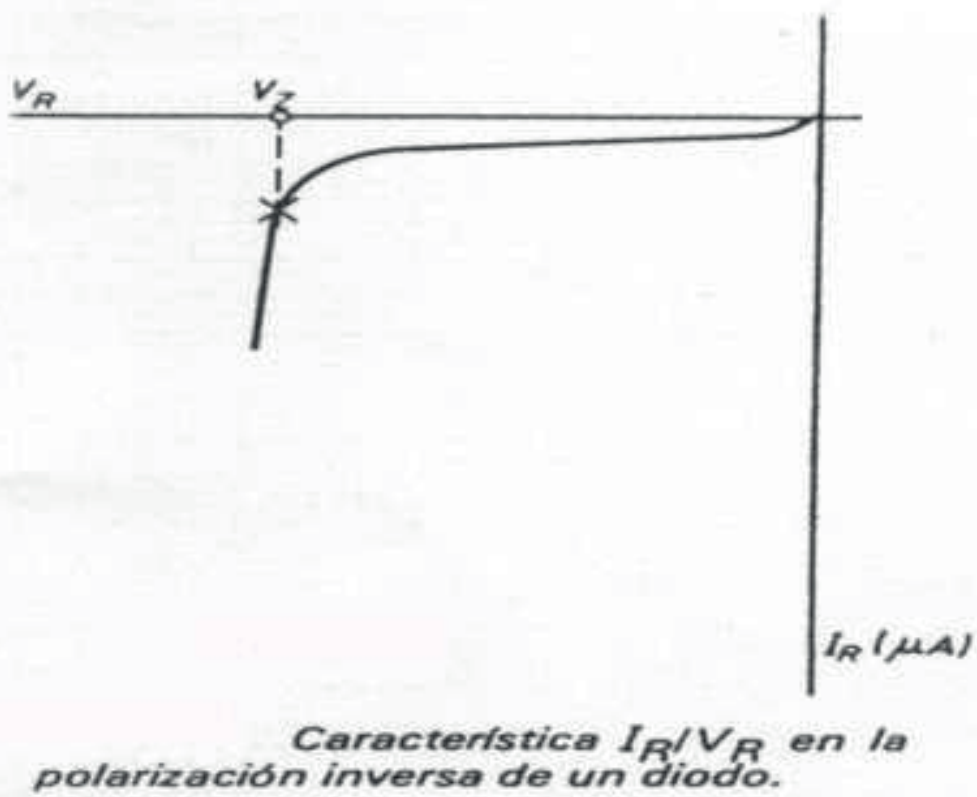

\section{El transistor}

Pasemos a la segunda combinación de cristales extrínsecos semiconductores, la que constituye el transistor. Brattain y Bardeen inventaron el primer transistor, denominado de puntas de contacto, que venía a ser, más o menos, como muestra la figura: 


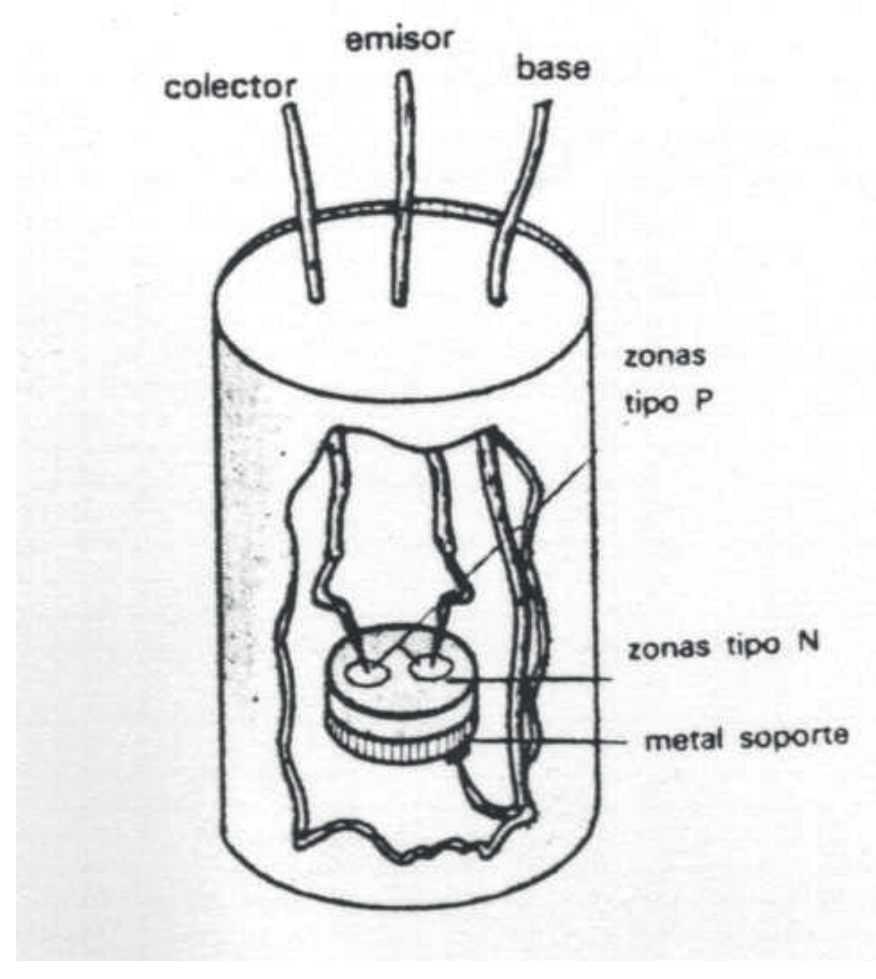

Posteriormente, en 1.949, Schockley inventó el transistor de unión, con lo que se dio paso a una nueva era: son estos transistores de unión los que actualmente se utilizan. Básicamente, un transistor está compuesto por tres semiconductores extrínsecos: dos del mismo tipo $\mathrm{N}$ o $\mathrm{P}$ y otro, contrario $\mathrm{P}$ o $\mathrm{N}$; uniendo uno de los iguales con el contrario y volviendo a unir con el restante, se obtendrán dos clases de transistores, uno PNP y el otro NPN. 


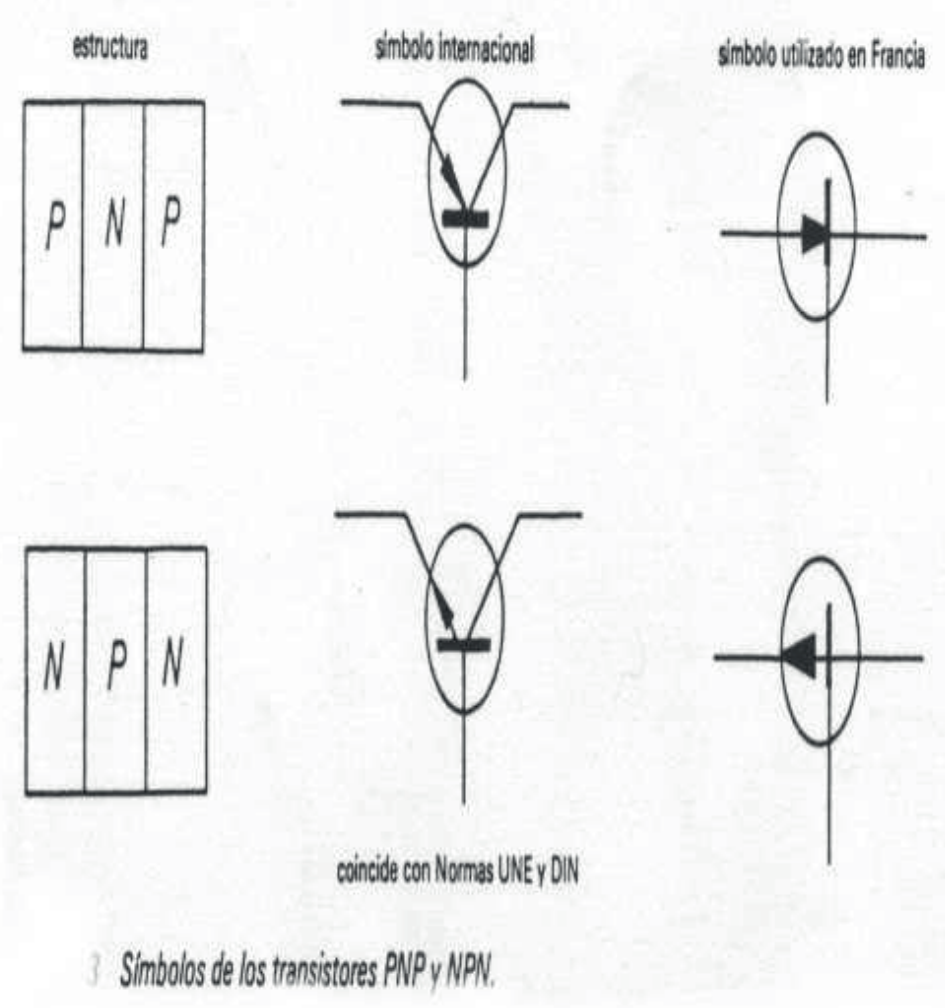

La zona central de las tres (la diferente) suele ser muy estrecha, mucho menor que las otras dos. Se podría también decir que un transistor es la unión de un semiconductor extrínseco $\mathrm{N}$ o P, a un lado o a otro de un diodo semiconductor. La zona estrecha del transistor, que es siempre la central (la emparedada), se denomina base, como consecuencia de que en el primer transistor sustentaba todo el resto. Luego, quedan dos zonas idénticas, o N o P, según sea NPN o PNP; estas zonas se llaman emisor, la una y colector, la otra. Emisor, la primera, porque es la que inyecta los portadores para la conducción y colector, la segunda, porque recibe todo, lo proveniente de la base y el emisor. A primera vista, parece como si cualquiera de estas zonas pudiera ser emisor o colector. Pero no es así: cada una es característica de una patilla. Es fácil descifrar, en un esquema, cuáles son las patillas correspondientes al Colector C, Emisor E y Base B; la misma facilidad entraña el saber si un transistor es NPN o PNP. El emisor es el terminal que lleva la flecha; la base es la que sujeta el esquema y lo soporta; y el colector, el restante, no tiene caracterización. Obsérvese que el primer 
transistor es PNP y la flecha pincha (recuérdese Pincha PNP), y análogamente en un transistor NPN la flecha no pincha (No Pincha NPN).

Compruébese cómo el transistor, mirado desde la base hacia los extremos, se comporta como dos diodos. El diodo base-colector se polariza siempre inversamente. Piénsese que lo que se pretende es controlar la corriente inversa de este diodo, lo cual sólo se puede hacer si se consigue aumentar los portadores inyectando electrones adicionales. Esto se hará a partir de nuestro segundo diodo: el de emisor-base. Para ello, se polariza de forma directa. Si, como ya se ha dicho, la base es muy estrecha, los electrones procedentes del emisor, que van muy acelerados, en vez de escaparse por la base, pasarán a gran velocidad por ella hacia el colector. Este proceso de conducción se llama efecto transistor, que consiste en aumentar la corriente inversa, o corriente de fuga, del diodo colector-base, o inyectar electrones adicionales. Si la base fuese muy ancha, sucedería que, al ser una zona $P$, existirían huecos que serían llenados por electrones procedentes del emisor $\mathrm{y}$, por tanto, disminuirían los inyectados en la zona de difusión base-colector (por eso se construye la base más estrecha). Si se disminuye o aumenta la inyección de portadores mayoritarios, disminuirá o aumentará la corriente de colector; esto también se puede explicar diciendo que, cuando se varía la resistencia base-emisor, cambia también la resistencia base-colector; de ahí el nombre de TRANSISTOR: TRANsfer reSISTOR (cambiador de resistencia).

\section{Fabricación de componentes de estado sólido}

Por último trataremos la fabricación de elementos semiconductores. Desde el descubrimiento de las aplicaciones de éstos al campo de la electrónica se han desarrollado muy diversas técnicas para obtener los mejores rendimientos y más amplia gama de dispositivos fabricados, con el fin de cubrir todas las necesidades posibles. Estas técnicas son aplicables a todos los elementos que se producen con 
materiales semiconductores mas, en el presente estudio, se explican aplicados a los transistores, a saber:

-Transistor de puntas de contacto: Es el procedimiento más antiguo y, en nuestros días, ya ha caído en desuso esta técnica. No obstante, a título de curiosidad, se explica aquí su fabricación. Sobre una pastilla de material semiconductor, de tipo N, se introducen las puntas de dos alambres de bronce fosforoso con separación de unas centésimas de milímetro. Los átomos de los alambres de contacto se esparcen dentro de la pastilla (base), creando dos regiones del tipo $\mathrm{P}$, que forman el emisor y colector. Este es el transistor que mostraba la figura 23.

-Transistor de aleación: Sobre una oblea de material semiconductor tipo $\mathrm{N}$, que constituye la base del transistor, se colocan dos pequeñas bolitas de indio, una a cada lado de la oblea, y el conjunto se calienta a elevada temperatura durante un corto espacio de tiempo, de manera que se produce una fusión; al enfriarse, el indio ha creado una zona del tipo $\mathrm{P}$, que forma el emisor: 

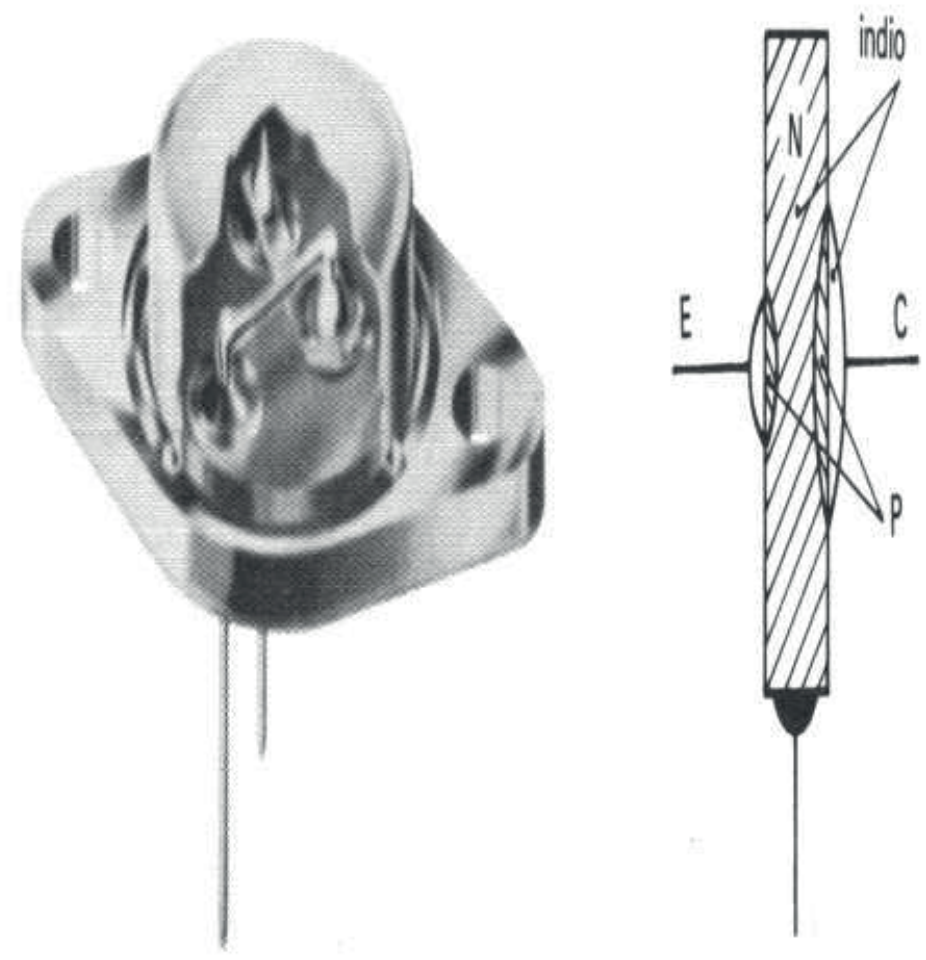

El colector se forma exactamente igual; pero, se procura que la superficie sea mayor. Las uniones y las superficies suelen ser grandes, respecto de otros transistores, pueden soportar intensidades elevadas y, por eso, se utiliza en etapas de salida. Su funcionamiento en alta frecuencia no es muy bueno, ya que la base es relativamente grande.

-Transistor de difusión: Una pastilla de material, tipo $\mathrm{P}$ o $\mathrm{N}$, se introduce en un horno, a elevada temperatura, en el que ya existen átomos de impureza, en forma de gas. Transcurrido un tiempo, y tras enfriarse, se comprueba que el gas (por ejemplo, arsénico) ha penetrado en la pastilla, unos micrones. La profundidad alcanzada se puede controlar, fácilmente, con la temperatura y el tiempo de exposición. Aprovechando esta técnica de difusión se fabrica el transistor de aleación difusa. Partiendo de una pastilla de germanio, tipo P, que forma el colector del transistor, mediante vapores de un elemento donador se forma una capa $\mathrm{N}$ sobre la pastilla. 
Sobre la misma cara de la pastilla se colocan dos bolitas, una con impurezas N y P y la otra, con impurezas sólo N. Sometiendo este conjunto a un tratamiento térmico, las bolitas se difunden por la capa N con que se había dotado a la pastilla. Gracias a las características de los materiales se consigue que los átomos de impureza $\mathrm{N}$ penetren más que los $\mathrm{P}$ y formen una zona $\mathrm{N}$. Por el contrario, dos átomos, que casi no han penetrado, forman una zona $\mathrm{P}$, que constituirá el emisor:
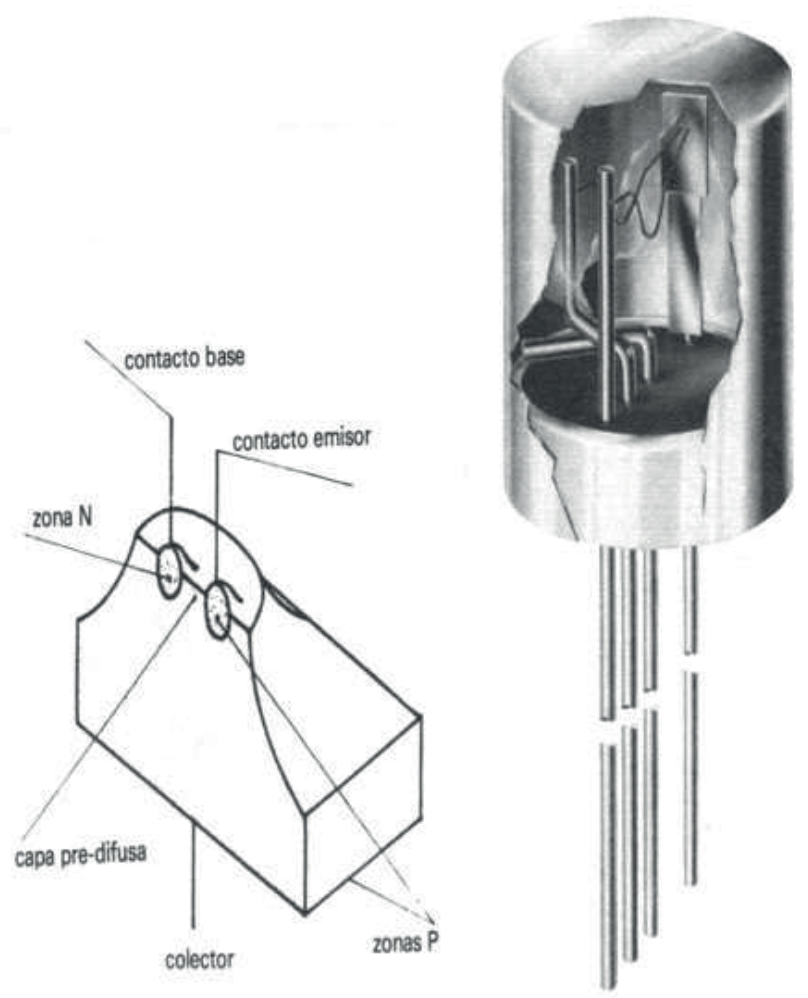

De esta forma y, por el siguiente orden, queda constituido el transistor:

Emisor, constituido por los átomos P de la bolita PN.

Base, formada por la difusión de los átomos $\mathrm{N}$ y la capa depositada, por vapor. 
Colector, formado por la pastilla base de que se ha partido. La bolita de tipo N sirve de conexión con la zona $\mathrm{N}$ del transistor.

-Transistor de barrera superficial: A una oblea de material semiconductor se le ataca con dos chorros muy delgados de electrólito y, al mismo tiempo, se hace pasar una corriente eléctrica, que origina una conexión por ambos lados; fruto de ésta es el espesor de la base, que llega a ser muy fina. Conseguido el espesor deseado, mediante un depositado electroquímico, con el material apropiado, se obtienen el emisor y colector:

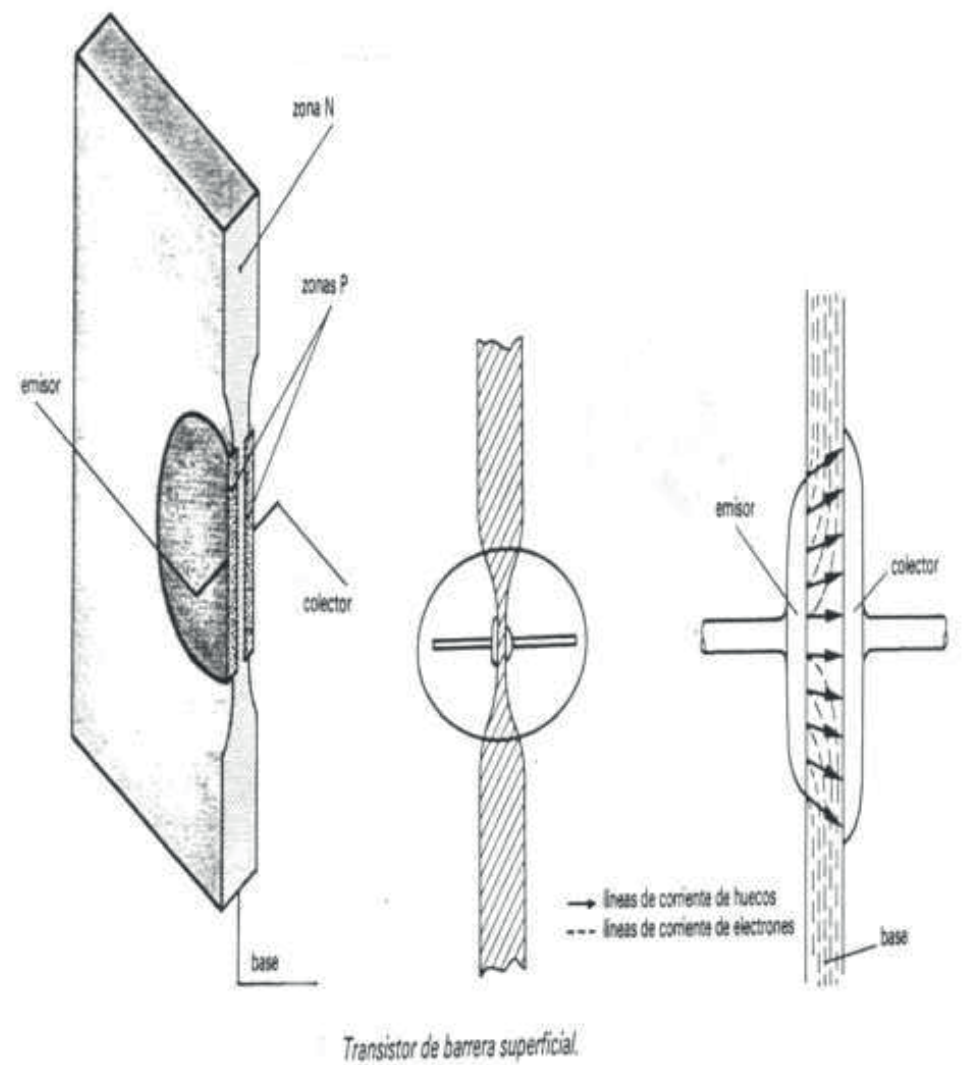

-Transistor mesa: Sobre una pastilla de material semiconductor $P$, que sirve de colector, se deposita, por difusión al vapor, una capa de material N. En una parte de esta capa, se sobrecompensan los donadores, mediante difusión de aceptadores y, 
así, se forma la zona P, que constituye el emisor. Para dotar de patillas de contacto al emisor y la base, (no al colector porque el propio chasis sirve), se puede utilizar el sistema de evaporar y depositar en forma de tiras un material adecuado en las zonas respectivas. El nombre lo recibe de su forma, semejante a una mesa:

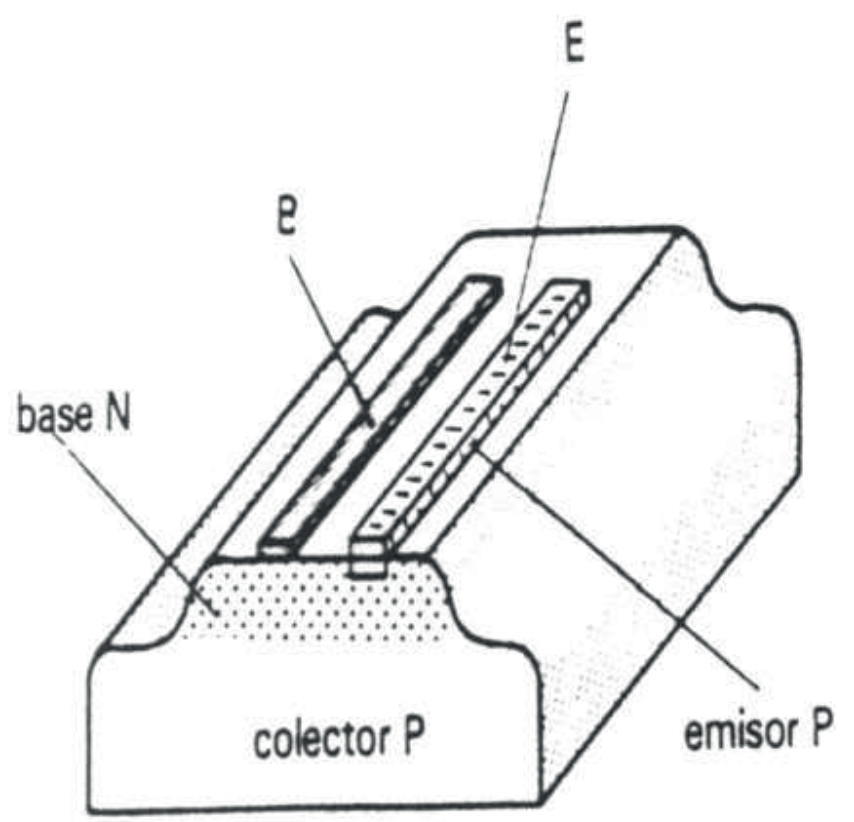

-Transistor epitaxial: Una pastilla de semiconductor P o N, con impurezas, sirve de portadora del transistor. Por medio de vapor, se deposita una capa de material semiconductor, análogo al de la pastilla, y se forma una red de capa epitaxial, cuya resistencia es superior a la del material portador. La capa epitaxial forma el colector y su contacto es la pastilla portadora. La base y el emisor, que se colocan a continuación, y por ese orden, sobre la capa epitaxial, se forman por la técnica de difusión o de aleación difusa. Por este método, se consigue reducir la resistencia del colector: 


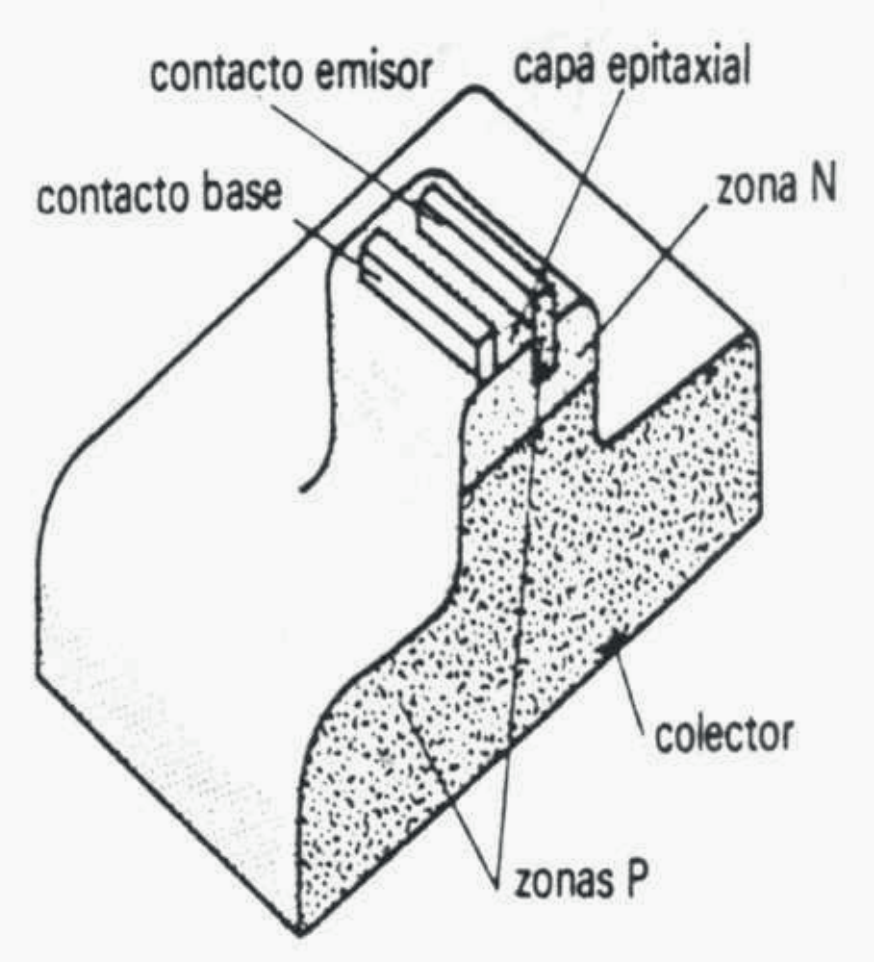

-Transistor planar: Sobre una pastilla de material N, que servirá de colector, se produce una oxidación en la parte superior, que evita la propagación de impurezas. Del emisor. Eliminado este óxido por procedimientos químicos, se deposita un nuevo material que forma la base y que se une al colector por difusión. Otra capa de óxido cierra los posibles puntos abiertos. De nuevo, por procedimiento químico, se abre otra ventana, sobre la base en esta ocasión, y, por igual procedimiento, se forman el emisor y la unión emisor-base. Se recubre de óxido el emisor y se proporcionan contactos a los tres cristales, encapsulando adecuadamente el conjunto: 


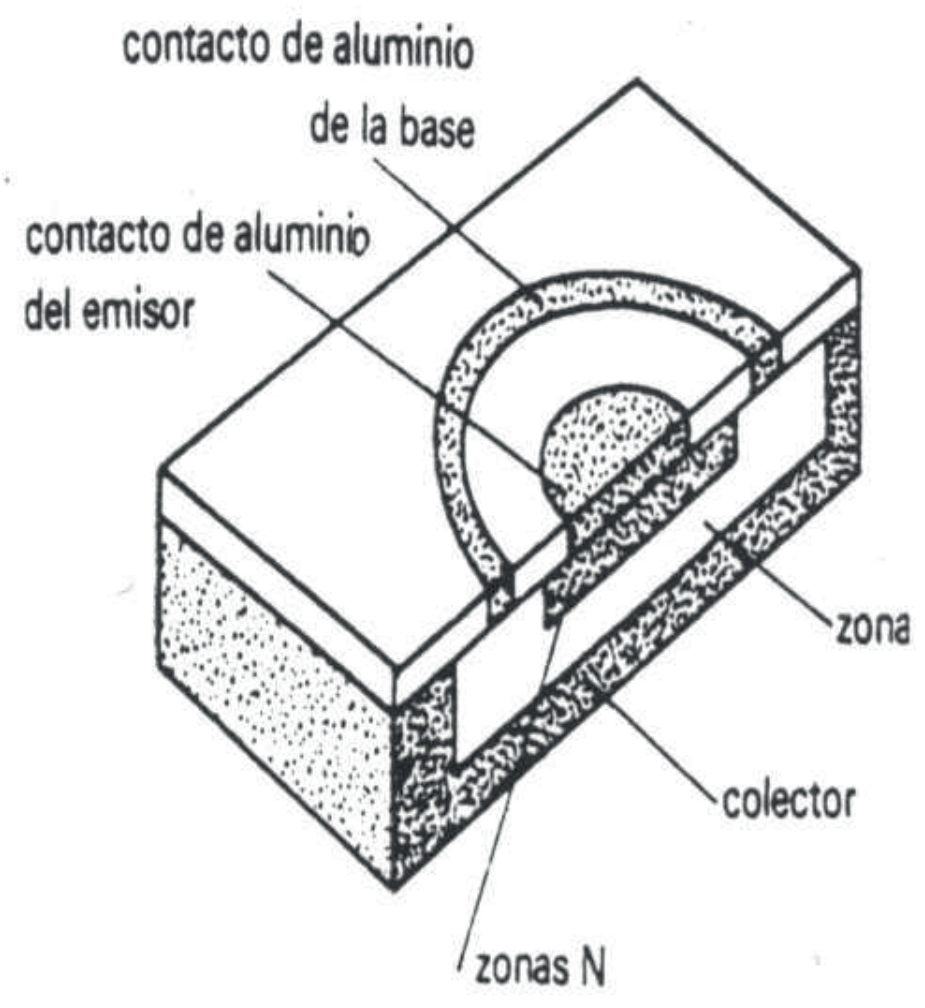

